\title{
EVASÃO FISCAL DO IMPOSTO SOBRE A RENDA: UMA ANÁLISE DO COMPORTAMENTO DO CONTRIBUINTE ANTE O SISTEMA IMPOSITIVO BRASILEIRO
}

\author{
Marcelo Lettieri Siqueira ${ }^{\S}$ \\ Francisco S. Ramos
}

\begin{abstract}
RESUMO
O objetivo do presente artigo é explicar como o comportamento do contribuinte determina o nível de evasão do Imposto sobre a Renda da Pessoa Física (IRPF) no Brasil, por meio de uma expansão do modelo de Allingham e Sandmo (1972), de forma a incorporar as características específicas do sistema de imposição do IRPF e, assim, fornecer subsídios à autoridade tributária brasileira para a definição de estratégias de auditoria fiscal. Os resultados indicam que aumentos nas probabilidades de auditoria, nas penalidades, na alíquota marginal do imposto e na eficiência das auditorias das declarações reduzem a evasão do Imposto sobre a Renda da Pessoa Física. Além disso, ficou evidente que há diferenças de comportamento entre regiões, demonstrando que grupos distintos de contribuintes avaliam de forma diferente os riscos da atividade de sonegação, parecendo conhecer bem as diferentes probabilidades de detecção.
\end{abstract}

Palavras-chave: evasão fiscal, Imposto sobre a Renda, auditoria, comportamento do contribuinte.

\begin{abstract}
The objective of this paper is to explain as the behavior of the taxpayer determines the level of personal income tax evasion in Brazil, through an expansion of the Allingham e Sandmo's model (1972), where we incorporate the specific characteristics of the Brazilian tax law enforcement system, to supply subsidies to the Brazilian tax authority in the design of tax audit rules. The results indicate that increases in the probabilities of tax audit, in the penalties, in the marginal tax and in the efficiency of the internal tax audit reduces the evasion of the personal income tax. Moreover, it was evident that it has differences of behavior between Regions, demonstrating that distinct groups of taxpayers evaluate of different form the risks of the tax evasion, seeming to know the different probabilities of detection.
\end{abstract}

Key words: tax evasion, income tax, audit rules, taxpayer behavior.

JEL classification: H26, D81, K42.

$\S$ Professor da Pós-graduação em Economia - CAEN/UFC. Doutor em Economia pelo PIMES/UFPE. End.: Rua Carlos Vasconcelos, 636/1001 - Meireles, Fortaleza - CE, CEP: 60115-170, Fones: (85) 3268-3867 e 9121-9480. E-mail: lettieri@caen.ufc.br

a Prof. do Departamento de Economia - PIMES. Doutor em Economia pela Universite Catholique de Louvain. End.: Av. dos Economistas, s/n - Cidade Universitária - Recife - PE, CEP: 50.670-901, Fones: (81) 3271-8716. E-mail: fsr@ufpe.br, ramosfs@hotmail.com. O autor agradece a Bolsa de Produtividade em Pesquisa do CNPq.

Recebido em setembro de 2004. Aceito em julho de 2006. 


\section{INTRODUÇÃO}

A evasão fiscal (ou sonegação, como é comumente conhecida) é um problema tão antigo quanto os impostos em si. Sua ocorrência traz fortes implicações para o funcionamento do sistema tributário e da economia como um todo. Além de ser um dos principais problemas que as administrações tributárias enfrentam, tal fenômeno afeta a eficiência econômica, reduz a eqüidade tributária e compromete as ações de política econômico-tributária.

Portanto, controlar os níveis de evasão fiscal deve ser um dos principais objetivos das autoridades tributárias. No entanto, fazer com que os contribuintes paguem corretamente os tributos é uma tarefa bastante árdua, dados os limites estruturais da economia, os diversos incentivos à atividade de sonegação e, em alguns casos, a aceitação social deste comportamento.

Apesar dos grandes esforços despendidos pela autoridade tributária brasileira, a evasão fiscal no Brasil ainda é bastante acentuada. Se por um lado os contribuintes já pagam muitos tributos (a carga tributária no Brasil alcançou 37\% do PIB em 2005), por outro, há um sentimento generalizado de que o governo não aplica eficientemente os valores arrecadados, contribuindo para um aumento do desejo de sonegar.

No estudo da evasão fiscal, outra dificuldade surge: não há estimativas precisas do seu nível. No Brasil, a imprensa nacional já chegou a publicar notícias segundo as quais para cada Real arrecadado um seria sonegado. ${ }^{2}$ Trata-se, obviamente, de uma informação absurda, que elevaria a nossa carga tributária (já bastante alta) a patamares insuportáveis. Estimativas mais realistas situam o nível de sonegação em valores que variam de $15 \%$ a $40 \%$ da arrecadação potencial, o que já é bastante elevado. A título de comparação, nos Estados Unidos, o IRS ${ }^{4}$ estimou uma evasão de cerca de $17 \%$ da arrecadação do imposto sobre a Renda (Slemrod; Yitzhaki, 2000); na Rússia, a Fundação "Bureau of Economic Analysis" estimou uma evasão de 42,7\% para o ano de 1997 (BEA, 1998); e para o Chile este porcentual foi de $26 \%$ no ano de 1995 (Jorratt, 1998).

Por ser um fenômeno bastante complexo, a evasão fiscal pode ser analisada de uma variedade de perspectivas. ${ }^{5}$ Isto porque a postura do contribuinte é influenciada por muitos fatores, incluindo os aspectos da justiça tributária, a prevalência das normas sociais, a avaliação dos benefícios públicos recebidos e a possibilidade de que a evasão esteja sendo detectada e punida. Sem considerar questões éticas e sociológicas, a análise econômica da evasão fiscal ${ }^{6}$ focou-se inicialmente em como o comportamento sonegador pode ser dissuadido por meio da ameaça de detecção e aplicação de sanções.

Nessa linha de pensamento, os primeiros modelos microeconômicos de evasão fiscal adotaram a abordagem do modelo sobre escolhas criminosas de Becker (1967). Allingham e Sandmo (1972) foram os pioneiros na aplicação da idéia ao estudo da evasão fiscal. O modelo proposto por eles descreve a evasão do imposto sobre a renda como um processo de tomada de decisão de portfólio, utilizando a teoria da utilidade esperada desenvolvida por von Neumann e Morgenstern. Neste sentido, supõem que um contribuinte racional representativo considera a renda omitida (ou a evasão da ren-

1 Wasilewski (2001) estimou a evasão do Imposto sobre a Renda da Pessoa Física no Brasil em 21,91\%, 20,02\% e 16,39\% nos anos de 1996, 1997 e 1998, respectivamente.

2 Ver, por exemplo, matéria do Jornal da Tarde, seção Política, de 31 de dezembro de 2003.

3 Ver Wasilewski (2001), por exemplo.

4 Sigla para Internal Revenue Service, a Receita Federal Americana.

5 Uma análise minuciosa das principais teorias e evidências empíricas sobre evasão fiscal pode ser vista em Siqueira e Ramos (2005).

6 Revisões detalhadas a respeito deste tema estão disponíveis nas monografias de Cowell (1990) e de Roth, Scholtz e Witt (1989), nas revisões de literatura de Andreoni, Erard e Feinstein (1998), Franzoni (1999) e de Slemrod e Yitzhaki (2000) e na tese de doutoramento de Siqueira (2004). 
da) um ativo de risco, que depende da possibilidade de detecção da omissão e de sua conseqüente punição e, a partir de então, maximiza uma função de utilidade esperada. As principais variáveis do modelo são, portanto, a renda total recebida, a alíquota marginal do imposto, a probabilidade de detecção da evasão, a penalidade a ser aplicada, o grau de aversão ao risco e o grau de honestidade do contribuinte. Após a especificação matemática do modelo, eles derivam um máximo interior e examinam a estática comparativa e os impactos da imposição tributária sobre o bem-estar.

Esse modelo básico dá uma boa idéia das decisões de evasão dos contribuintes em uma estrutura muito simples: os impostos e as penalidades são proporcionais, a probabilidade de auditoria é constante e somente uma forma de evasão está disponível (a subdeclaração da renda tributável). Além disto, supõe-se que o contribuinte segue a teoria da utilidade esperada e é perfeitamente amoral, isto é, toma decisões em obediência exclusiva às conseqüências para a sua renda líquida.

No entanto, está perfeitamente claro para muitos pesquisadores que a evasão não pode ser explicada inteiramente pelos incentivos financeiros gerados pelo nível de imposição da lei. (Graetz; Wilde, 1985; Elffers, 1991). Parece pouco plausível que as atividades de imposição do governo sozinhas sejam responsáveis pelos níveis de obediência à legislação tributária observados na maioria dos países. Ou seja, o modelo básico, fundado unicamente na teoria da utilidade esperada, é certamente incapaz de explicar este comportamento.

Todas as hipóteses desse modelo básico foram objeto de críticas, e modelos teóricos baseados em hipóteses alternativas foram desenvolvidos tentando introduzir formalmente outros fatores que parecem ser relevantes para a decisão individual de evadir. Uma extensão imediata foi permitir que o indivíduo escolhesse a renda a declarar juntamente com outras variáveis adicionais, tais como a oferta de trabalho, proposta por Pencavel (1979) e Cowell (1981), ou a escolha ocupacional, sugerida por Pestieau e Possen (1991), e esquemas complementares de elisão fiscal, como implementado por Cross e Shaw (1982). Penas alternativas e alíquotas não-lineares foram consideradas por Pencavel (1979) e Kesselman (1989), e o impacto da complexidade e incerteza sobre outros parâmetros fiscais foi analisado por Alm (1988) e Scotchmer e Slemrod (1989). Ao constatar que um número crescente de indivíduos costuma pagar profissionais para a elaboração de suas declarações de rendimentos, o efeito deste comportamento sobre a evasão foi examinado por Scotchmer (1989) e Reinganum e Wilde (1991). Ademais, como alguns indivíduos recebem algum serviço do governo por seus impostos pagos, Cowell e Gordon (1988) mostraram que os serviços prestados pelo governo afetam as decisões de evasão, ou seja, os indivíduos pagam tributos porque eles valoram o que eles recebem em troca, e eles pagam mais à medida que o governo é mais efetivo em prover o que eles valorizam. (Wadhawan; Gray, 1998).

A maior parte dessa literatura argumenta que a provisão voluntária de bens públicos nem sempre pode ser vista como um jogo do dilema do prisioneiro no qual cada indivíduo tem um incentivo para deixar a provisão para os outros. (Alm, 1998). De fato, em muitos casos os indivíduos irão contribuir para o bem público; ou seja, eles pagarão seus tributos. Neste contexto, a decisão do indivíduo em contribuir - ou não evadir - dependerá de sua percepção quanto à contribuição dos outros, agora e no futuro. (Alm, 1998). Outro aspecto importante que tem sido considerado é que os indivíduos podem responder positivamente a incentivos dados a quem é auditado e se mostrar honesto, como demonstrou Falkinger e Walther (1991).

Como visto, diversos fatores econômicos podem ser incluídos no modelo básico de Allingham e Sandmo (1972) e, com certeza, outros fatores que não foram mencionados aqui podem ser ain-

7 Variantes e extensões dessa análise incluem os trabalhos de Srinivasan (1973), Kolm (1973), Singh (1973), Yitzhaki (1974, 1987), McCaleb (1979), Nayak (1978), Pencavel (1979), Gottlieb (1979), Christiansen (1990), Cross e Shaw (1982), Koskela (1983a, 1983b), Cowell e Gordon (1988), Toma (1989), Falkinger (1991), Landskroner et al. (1990), e Chu (1990a, 1990b), todos citados em Franzoni (1999). 
da mais relevantes. Até agora, o que se constata é que nenhuma teoria simples tem sido capaz de incorporar mais do que alguns poucos desses fatores de uma forma significativa. Infelizmente, os numerosos refinamentos e extensões complicam consideravelmente as análises teóricas e geralmente impossibilitam que quaisquer resultados analíticos bem definidos sejam obtidos.

Existem também alguns trabalhos que expandem o modelo básico de escolha individual, introduzindo alguns aspectos comportamentais e motivacionais considerados explícitos por outras ciências sociais. Muitos desses aspectos podem ser incorporados na Teoria da Perspectiva desenvolvida por Kahneman e Tversky (1979). Outras abordagens que consideram fatores tais como desvios de comportamentos, características sociais e situacionais, contextos sociais e teoria da atribuição têm sido aplicadas com algum sucesso. ${ }^{8}$

As observações antecedentes oferecem uma estrutura analítica para tratar alguns aspectos relevantes da evasão fiscal, sugerindo causas e possíveis remédios, mas não têm sido suficientes para analisar o fenômeno em toda a sua complexidade. Obviamente, a resposta não está unicamente em mudanças marginais na prática da imposição. No entanto, como as atitudes sociais e morais - que certamente têm um papel muito importante - são muito lentas em promover as mudanças necessárias e não são facilmente afetadas por políticas públicas, estudar o sistema de imposição padrão, baseado no binômio auditoria mais penalidade, ainda permanece crucial. As evidências empíricas sugerem que um regime mais estrito de imposição (maior probabilidade de detecção e maior punição) provavelmente irá induzir a uma maior obediência.

Neste contexto, o objetivo do presente trabalho é explicar como o comportamento do contribuinte determina o nível de evasão do Imposto sobre a Renda da Pessoa Física (IRPF) no Brasil, por meio de uma expansão do modelo de Allingham e Sandmo (1972), de forma a incorporar as características específicas do sistema de imposição (fiscalização e punição) deste imposto. Tal sistema baseia-se num esquema de dupla auditoria, por meio do qual o contribuinte está sujeito, primeiramente, a uma auditoria interna de sua declaração de rendimentos e, em algum período futuro, a uma auditoria externa, momento este em que são confrontadas diversas informações não presentes na declaração de rendimentos inicialmente entregue à autoridade tributária. De posse dos determinantes do comportamento do contribuinte, a autoridade tributária pode traçar políticas de imposição que visem à redução da evasão.

\section{O MODELO}

O modelo aqui desenvolvido parte da idéia básica de Allingham e Sandmo (1972) de que a evasão do imposto sobre a renda pode ser modelada como um processo de tomada de decisão de portfólio, utilizando a teoria da utilidade esperada de Von Neumann-Morgenstern.

Com o objetivo de analisar o comportamento do contribuinte diante do sistema impositivo brasileiro e das ações de política tributária que visem à redução da evasão, o modelo de Allingham e Sandmo (1972) será expandido, de forma a permitir que, mesmo que o contribuinte seja flagrado na auditoria interna da sua declaração de rendimentos (que daqui por diante será denominada “revisão de MALHA"), parte da evasão pode não ser detectada; e somente uma auditoria externa (denominada, aqui, de FISCALIZAÇÃO), realizada em função de outras informações econômicas sobre o contribuinte, poderia detectar esta parcela não observada na revisão de MALHA. Esta é a primeira grande diferença entre o modelo aqui proposto e o modelo de Allingham e Sandmo (1972): existe a possibilidade de detecção apenas parcial da evasão, e o contribuinte sabe disto.

8 Ver Roth, Scholz e Witte (1989) e Long e Swingen (1991) para uma discussão e avaliação de muitas dessas teorias alternativas. 
É importante ressaltar que o modelo aqui proposto tenta incorporar o fato de que o contribuinte, por meio do conhecimento perfeito que tem de todas as suas fontes de renda, pode ocultar uma fração dela, via decomposição desta em duas partes: uma que ele sabe ser identificável pela SRF, por meio de uma análise de sua própria declaração, e uma outra, cuja identificação pela autoridade tributária somente se dá mediante uma fiscalização mais minuciosa, que devido aos custos é extremamente rara (de baixíssima probabilidade).

Assume-se, então, que a probabilidade de ser flagrado na revisão de MALHA ${ }^{9}$ é dada por $\mathbf{p}_{1}$, a probabilidade de ser submetido a uma FISCALIZAÇÃO é dada por $\mathbf{p}_{\mathrm{x}}$, sendo $\mathbf{p}_{\mathrm{x}}=\mathrm{p}_{2}$, se o contribuinte não tiver caído em MALHA; e $\mathbf{p}_{\mathrm{x}}=\mathrm{p}_{3}$, se o contribuinte caiu em MALHA.

A partir dessas considerações, adota-se a hipótese de que a revisão de MALHA identifica uma fração da evasão, enquanto a FISCALIZAÇÃO, por ser mais minuciosa, identificaria toda ela. No entanto, tendo o contribuinte caído em MALHA, a possibilidade de ele ser fiscalizado é ainda maior do que a do contribuinte que teve a sua declaração "aceita" na revisão interna. ${ }^{10}$

O comportamento ótimo do contribuinte origina-se, então, da maximização da função utilidade esperada, $\mathbf{E}\left[\mathbf{U}_{\mathbf{i}}(\mathbf{Y})\right]$, quase-côncava $\left(\mathbf{U}_{\mathbf{i}}{ }^{\prime}(\mathbf{Y}) \geq \mathbf{0}\right.$ e $\left.\mathbf{U}_{\mathbf{i}}{ }^{\prime}{ }^{\prime}(\mathbf{Y}) \leq \mathbf{0}\right)$. Esta função de utilidade cardinal tem a renda disponível do contribuinte, $\mathbf{Y}$ (exógena e conhecida por ele, mas não pela autoridade tributária), como único argumento. A quase-concavidade da função utilidade esperada indica que o contribuinte é neutro ou tem aversão ao risco.

A existência de duas possibilidades de auditoria (MALHA e FISCALIZAÇÃO) torna possível a ocorrência das seguintes combinações de probabilidades: ${ }^{11}$

$\mathbf{p}_{1} \mathbf{p}_{3} \rightarrow$ probabilidade de o contribuinte ter a sua declaração revisada (MALHA) e, posteriormente, ser fiscalizado (Situação A).

$\mathbf{p}_{\mathbf{1}}\left(\mathbf{1}-\mathbf{p}_{\mathbf{3}}\right) \rightarrow$ probabilidade de o contribuinte apenas ter a sua declaração revisada em MALHA (Situação B).

$\left(\mathbf{1}-\mathbf{p}_{1}\right) \mathbf{p}_{2} \rightarrow$ probabilidade de o contribuinte ser submetido a, tão-somente, uma fiscalização externa (Situação C).

$\left(\mathbf{1}-\mathbf{p}_{1}\right)\left(\mathbf{1}-\mathbf{p}_{\mathbf{2}}\right) \rightarrow$ probabilidade de o contribuinte não ter a sua declaração revisada (MALHA) e nem ser fiscalizado (Situação $D$ ).

Seja I a renda bruta do contribuinte, e $\mathbf{R}$ a sua renda tributável real. ${ }^{12} \mathrm{O}$ contribuinte declara uma renda tributável $\mathbf{X}, \operatorname{com}(\mathbf{R}-\mathbf{X}) \geq 0 .{ }^{13}$ A renda declarada, $\mathbf{X}$, será, portanto, a variável de decisão do contribuinte.

A autoridade tributária estabelece uma alíquota marginal efetiva igual a $\mathbf{t}(\mathbf{t}<1)$ e impõe uma multa igual a $\theta_{1}$, incidente sobre a parcela da evasão detectada na revisão de MALHA, e/ou $\theta_{2}$, incidente sobre a evasão detectada na FISCALIZAÇÃO. Ao ser detectado na sonegação, o contribuinte deve pagar, também, o imposto que deixou de recolher por causa da evasão. ${ }^{14}$

9 Vamos supor que, tendo o contribuinte optado por ocultar parte de sua renda e sendo esta identificável pela revisão de MALHA, ao cair na MALHA, toda a renda aqui identificável passa a ser conhecida.

10 No âmbito da fiscalização do IRPF no Brasil, ao decidir fiscalizar um contribuinte, a SRF primeiramente analisa todas as informações declaradas por ele, sendo, portanto, efetuada (se já não o foi) a revisão de MALHA. A hipótese, portanto, aproxima-se bastante da realidade.

11 Ao cair em malha e/ou ser fiscalizado, toda a renda do contribuinte identificável em cada uma das formas de auditoria passa a ser conhecida pela Autoridade Tributária.

12 A renda tributável real é dada pela diferença entre a renda bruta e as deduções legalmente permitidas.

13 Estamos supondo que não há qualquer prêmio por declarar mais do que a renda tributável real e que, portanto, um contribuinte racional não irá fazê-lo.

14 Os modelos microeconômicos de evasão normalmente consideram incorporados na multa tanto o imposto que deixou de ser pago quanto a penalidade por não tê-lo feito corretamente, de forma que os valores da multa obedecem à relação $\mathbf{F} \geq 1$, em que $\mathrm{F}$ indica toda a penalidade pecuniária sofrida pelo contribuinte. No nosso caso teríamos, então, $\mathbf{F}_{\mathrm{i}}=1+\boldsymbol{\theta}_{\mathrm{i}}$. 
Supõe-se, ainda, que $\alpha \mathbf{E}$ seja a parcela da evasão detectada pela revisão de MALHA, e que a fiscalização detecta $\mathbf{E}$, em que $\mathbf{E}$ mede a evasão total cometida pelo contribuinte, expressa por t.(R - X). ${ }^{15}$ Desta forma, $\alpha$ determina o nível de eficiência da auditoria interna percebida pelo contribuinte, $\operatorname{com} \mathbf{0} \leq \alpha \leq \mathbf{1}$. Temos, portanto, a introdução de um parâmetro de eficiência da atividade de auditoria interna, o que contribui para uma ampliação dos parâmetros de imposição a serem trabalhados pela autoridade fiscal.

Assim, para cada uma das situações anteriormente descritas (A, B, C e D), ter-se-á as seguintes rendas disponíveis:

$$
\begin{aligned}
& \mathbf{Y}_{\mathbf{A}}=\Pi-\mathbf{t}\left[\alpha \theta_{1}+(\mathbf{1}-\alpha) \theta_{2}\right](\mathbf{R}-\mathbf{X}) \\
& \mathbf{Y}_{\mathbf{B}}=\Pi-\mathbf{t}\left[\left(\mathbf{1}+\theta_{1}\right) \alpha-\mathbf{1}\right](\mathbf{R}-\mathbf{X}) \\
& \mathbf{Y}_{\mathbf{C}}=\Pi-\mathbf{t} \theta_{2}(\mathbf{R}-\mathbf{X}) \\
& \mathbf{Y}_{\mathbf{D}}=\Pi+\mathbf{t}(\mathbf{R}-\mathbf{X})
\end{aligned}
$$

em que $\Pi=\mathbf{I}-\mathbf{t R}$ é a renda pós-imposto do contribuinte.

Seja $\mathbf{R M g}(\mathbf{Y})_{\mathrm{X}}$ a renda marginal derivada da declaração de uma unidade adicional de renda tributável ou, com um sinal negativo, o retorno da evasão de uma unidade de renda tributável. Assim, para cada uma das quatro situações acima descritas tem-se:

$$
\begin{aligned}
& \operatorname{RMg}\left(\mathbf{Y}_{\mathrm{A}}\right)_{\mathrm{X}}=\mathbf{t}\left[\alpha \theta_{1}+(1-\alpha) \theta_{2}\right] \\
& \operatorname{RMg}\left(\mathbf{Y}_{\mathrm{B}}\right)_{\mathrm{X}}=\mathbf{t}\left[\left(1+\theta_{1}\right) \alpha-1\right] \\
& \operatorname{RMg}\left(\mathbf{Y}_{\mathrm{C}}\right)_{\mathrm{X}}=\theta_{2} \mathbf{t} \\
& \operatorname{RMg}\left(\mathbf{Y}_{\mathrm{D}}\right)_{\mathrm{X}}=-\mathbf{t}
\end{aligned}
$$

Como $0 \leq \alpha \leq 1,0<\mathbf{t}<1, \theta_{1} \geq 0$ e $\theta_{2} \geq 0$, têm-se os seguintes sinais para as rendas marginais derivadas:

$$
\begin{aligned}
& \operatorname{RMg}\left(Y_{A}\right)_{X} \geq 0 \\
& \operatorname{RMg}\left(Y_{C}\right)_{X} \geq 0 \\
& \operatorname{RMg}\left(Y_{D}\right)_{X} \leq 0
\end{aligned}
$$

15 No presente modelo, supomos que $\alpha$ é conhecido do contribuinte, ou seja, ao escolher $\mathbf{X}$, ele sabe que uma parte da evasão, $\boldsymbol{\alpha}(\mathbf{R}$ - X), pode ser detectada numa análise simples de sua declaração, e o restante somente numa fiscalização mais profunda. Por exemplo, um contribuinte pode desejar sonegar uma determinada quantia do seu imposto devido, em parte, por meio da subdeclaração de sua renda do trabalho (e aqui ele sabe que uma simples auditoria em sua declaração pode detectar a subdeclaração) e, numa parte complementar, por meio da omissão de alguma outra renda não identificável na revisão de MALHA (neste caso, ele sabe que somente uma fiscalização direta o flagraria). 


$$
R M_{g}\left(Y_{B}\right)\left\{\begin{array}{l}
\geq 0, \text { se } \alpha \geq \frac{1}{1+\theta_{1}} \\
<0, \text { se } \alpha<\frac{1}{1+\theta_{1}}
\end{array}\right.
$$

Portanto, o retorno esperado líquido da evasão de uma unidade de renda tributável, $\mathbf{X}$, é dado por:

$$
\begin{aligned}
& \mathbf{E}_{-\mathrm{X}}=-\mathbf{p}_{1} \mathbf{p}_{3} \operatorname{RMg}\left(\mathrm{Y}_{\mathrm{A}}\right)_{\mathrm{X}}-\mathbf{p}_{1}\left(1-\mathbf{p}_{3}\right) \operatorname{RMg}\left(\mathrm{Y}_{\mathrm{B}}\right)_{\mathrm{X}}-\left(1-\mathbf{p}_{1}\right) \mathbf{p}_{2} \operatorname{RMg}\left(\mathrm{Y}_{\mathrm{C}}\right)_{\mathrm{X}} \\
& -\left(1-\mathrm{p}_{1}\right)\left(1-\mathrm{p}_{2}\right) \operatorname{RMg}\left(\mathrm{Y}_{\mathrm{D}}\right)_{\mathrm{X}}
\end{aligned}
$$

e o problema do contribuinte é o seguinte:

$$
\operatorname{Max} E[U(X)]=p_{1} p_{3} U\left(Y_{A}\right)+p_{1}\left(1-p_{3}\right) U\left(Y_{B}\right)+\left(1-p_{1}\right) p_{2} U\left(Y_{C}\right)+\left(1-p_{1}\right)\left(1-p_{2}\right) U\left(Y_{D}\right)(11)
$$

A Condição de Primeira Ordem (CPO) para o problema é dada por:

$$
\begin{aligned}
\phi= & \frac{\partial E[U]}{\partial X}=p_{1} p_{x} \operatorname{RMg}\left(Y_{A}\right) U^{\prime}\left(Y_{A}\right)+p_{1}\left(1-p_{x}\right) \operatorname{RMg}\left(Y_{B}\right) U^{\prime}\left(Y_{B}\right)+ \\
& +\left(1-p_{1}\right) p_{2} \operatorname{RMg}\left(Y_{C}\right) U^{\prime}\left(Y_{C}\right)+\left(1-p_{1}\right)\left(1-p_{2}\right) \operatorname{RMg}\left(Y_{D}\right) U^{\prime}\left(Y_{D}\right)=0
\end{aligned}
$$

A CPO (equação 11) permite que seja obtida a função implícita: ${ }^{16}$

$$
\mathbf{X}^{*}=\mathbf{X}\left(\mathbf{R}, \mathbf{p}_{1}, \mathbf{p}_{2}, \mathbf{p}_{3}, \mathbf{t}, \theta_{1}, \theta_{2}, \alpha\right)
$$

A Condição de Segunda Ordem (C2O) é satisfeita, dada a quase-concavidade da função utilidade:

$$
\begin{aligned}
D= & \phi_{X}=\frac{\partial^{2} E[U]}{\partial X^{2}}=p_{1} p_{3} \operatorname{RMg}\left(Y_{A}\right)^{2} U^{\prime \prime}\left(Y_{A}\right)+p_{1}\left(1-p_{3}\right) \operatorname{RMg}\left(Y_{B}\right)^{2} U^{\prime \prime}\left(Y_{B}\right) \\
& +\left(1-p_{1}\right) p_{2} \operatorname{RMg}\left(Y_{C}\right)^{2} U^{\prime \prime}\left(Y_{C}\right)+\left(1-p_{1}\right)\left(1-p_{2}\right) \operatorname{RMg}\left(Y_{D}\right)^{2} U^{\prime \prime}\left(Y_{D}\right) \leq 0
\end{aligned}
$$

O esquema a seguir mostra o conjunto de resultados possíveis em função da decisão do contribuinte e das probabilidades de auditoria interna (MALHA) e de FISCALIZAÇÃO.

16 No Apêndice 1, demonstram-se quais são as condições para a existência de uma solução interior para o problema do contribuinte. 
Figura 1 - Rendas disponíveis em cada situação de auditoria

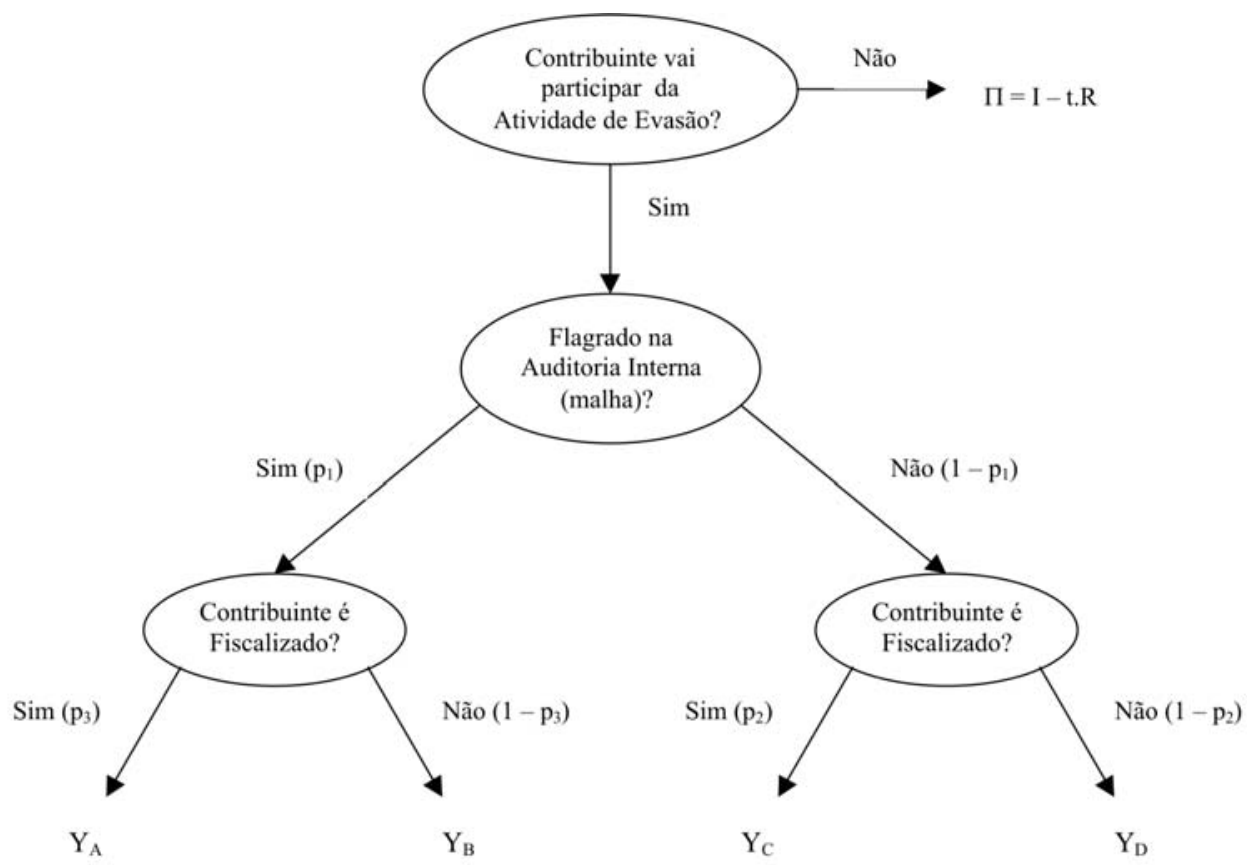

\section{RESUlTADOS PARA O IRPF}

Com o objetivo de verificar quais são os resultados fornecidos pelo modelo em função de dados reais do sistema de fiscalização do imposto sobre a renda da pessoa física no Brasil, ${ }^{17}$ elaborou-se um conjunto de simulações numéricas, cujas saídas foram apresentadas por meio de gráficos específicos da variável de decisão (renda declarada $-\mathbf{X}$ ) em função dos parâmetros de análise $\mathbf{p}_{1}$, $\mathbf{p}_{2}, \mathbf{p}_{3}, \mathbf{t}, \theta_{1}, \theta_{2}$ e $\alpha$. Tais resultados e a respectiva discussão estão apresentados nesta seção.

\subsection{Análise agregada (Brasil)}

\subsubsection{Calibragem do modelo agregado}

Para a calibragem do modelo, serão adotadas as seguintes hipóteses:

a) No que diz respeito à utilidade do contribuinte, trabalhar-se-á com a seguinte função isoelástica:

$$
U(X)=\frac{X^{1-\beta}}{1-\beta}
$$

na qual $\boldsymbol{\beta}$ é o coeficiente de aversão relativa ao risco, dado por $\boldsymbol{\beta}=\mathrm{Y} \cdot \mathrm{RA}(\mathbf{Y})$, sendo $\mathrm{RA}(\mathbf{Y})$ o Coeficiente de Aversão Absoluta ao Risco de Arrow-Pratt, definido como:

$$
R A(Y)=-\frac{U^{\prime \prime}(Y)}{U^{\prime}(Y)} \geq 0
$$

17 Foram utilizados os dados da SRF dos contribuintes Pessoas Físicas para o ano de 1998. 
Assim, o indivíduo terá aversão ao risco se $\boldsymbol{\beta} \geq 0$, e quanto maior $\boldsymbol{\beta}$, maior a aversão. Adotar-se-á para $\boldsymbol{\beta}$, na presente simulação, o valor de 1.8, conforme sugerido por Karni e Schmeider (1990) e Epstein (1992), ambos citados em Bernasconi (1998). A adoção de uma função utilidade isoelástica é bastante comum em estudos de comportamento diante do risco e por isso optou-se por ela. Quanto ao valor de $\boldsymbol{\beta}$, dada a inexistência desse tipo de estimativa para o Brasil, o ideal seria realizar pesquisas com os contribuintes de forma a dimensioná-lo adequadamente. No entanto, a dificuldade de se empreender tal pesquisa justifica a adoção, neste primeiro momento, do valor de 1.8 utilizado em outros estudos de evasão fiscal. ${ }^{18}$

b) As probabilidades de auditoria serão dadas por: ${ }^{19}$

$$
\begin{aligned}
& p_{1} \equiv \frac{N^{\mathrm{o}} \text { Total de Declarações Auditadas (Malha) }}{N^{\mathbf{o}} \text { Total de Declarações Entregues }} \\
& p_{2} \equiv \frac{N^{\mathrm{o}} \text { Total de Contribuintes Apenas Fiscalizados }}{N^{\mathrm{o}} \text { Total de Contribuintes }} \\
& p_{3} \equiv \frac{N^{\mathrm{o}} \text { de Contribuintes em Malha e Fiscalizados }}{N^{\mathrm{o}} \text { Total de Contribuintes em Malha }}
\end{aligned}
$$

O número total de declarações auditadas corresponde ao total de declarações que foram retidas na malha fina da $\mathrm{SRF} ;{ }^{20}$ o número total de declarações entregues corresponde ao total recepcionado pelos sistemas da Receita Federal; o número total de contribuintes apenas fiscalizados refere-se àqueles que foram diretamente fiscalizados pela SRF, independentemente de indícios obtidos de suas declarações de rendimentos ${ }^{21}$ e que, portanto, não tiveram suas declarações retidas em malha; o número total de contribuinte em malha e fiscalizados corresponde àqueles contribuintes que foram fiscalizados com base em indícios obtidos a partir de suas declarações previamente retidas em malha; e o número total de contribuintes foi estimado com base na População Economicamente Ativa (PEA) que ganha mais de 5 salários mínimos. ${ }^{22}$

Considerando os dados para 1998, apresentados na tabela a seguir, obtêm-se os seguintes valores para as probabilidades: $\mathbf{p}_{1}=0.06247, \mathbf{p}_{2}=0.00178$ e $\mathbf{p}_{3}=0,01493$.

Tabela 1 - Dados do sistema de arrecadação e fiscalização do IRPF

\begin{tabular}{llcccc}
\hline Ano & $\begin{array}{c}N^{0} \text { total de } \\
\text { declarações } \\
\text { entregues }\end{array}$ & $\begin{array}{c}\text { Retidas em } \\
\text { malha } \\
\text { (Quant.) }\end{array}$ & $\begin{array}{c}\text { Após caírem } \\
\text { em malha }\end{array}$ & $\begin{array}{c}\text { Outras } \\
\text { fiscalizações }\end{array}$ & Total \\
\hline 1997 & 10.446 .083 & 577.353 & 5.822 & 7.458 & 13.280 \\
1998 & 11.056 .037 & 690.653 & 10.309 & 8.692 & 19.001 \\
1999 & 12.340 .664 & 726.073 & 63.535 & 11.612 & 75.147 \\
2000 & 13.906 .145 & 1.223 .101 & 9.785 & 12.957 & 22.742 \\
\hline
\end{tabular}

18 Ver, por exemplo, Bernasconi (1998).

19 Ver discussões sobre o uso de freqüências relativas para a definição das probabilidades em Witte e Woodbury (1985) e Pommerehne e Weck-Hannemann (1996).

20 A SRF utiliza a nomenclatura INCIDÊNCIA EM MALHA para esse total de declarações que foram retidas na malha fina.

21 São referentes às fiscalizações diretas oriundas de denúncias, de investigação do Sistema de Inteligência da Receita ou de coleta de informações sobre os contribuintes que não constam de suas declarações, tais como: extratos de cartões de crédito, movimentação bancária (CPMF), aquisições e vendas imobiliárias etc.

22 Foi escolhido esse limite por ser o valor fornecido pelo IBGE que mais se aproxima do valor definido pela legislação do IRPF para a faixa de renda isenta do imposto. Em 1998, por exemplo, os rendimentos inferiores a $R \$ 900,00$ mensais eram isentos e o salário mínimo era de $\mathrm{R} \$ 130,00$. 


\begin{tabular}{cccccc}
\hline \multirow{2}{*}{ Ano } & \multirow{2}{*}{$\begin{array}{c}N^{0} \text { total de } \\
\text { contribuintes }\end{array}$} & & \multicolumn{3}{c}{ Rendimentos e imposto (milhões) } \\
\cline { 3 - 5 } & (PEA não isenta) & Rend. brutos & Rend. líquidos & Imp. devido & Alíquota média (\%) \\
\hline 1997 & 10.423 .638 & $199.646,79$ & $151.106,67$ & $14.225,89$ & 9,41 \\
1998 & 10.667 .983 & $214.039,26$ & $160.458,85$ & $16.564,79$ & 10,32 \\
1999 & 10.914 .000 & $255.445,98$ & $190.374,90$ & $19.947,01$ & 10,48 \\
2000 & 11.161 .689 & $276.149,34$ & $205.332,93$ & $21.638,12$ & 10,54 \\
\hline
\end{tabular}

Fonte: SRF e IBGE/PNAD 1999.

Notas: (1) Conforme já mencionado, o número total de potenciais contribuintes foi estimado com base na PEA que ganha mais de 5 salários mínimos. Ele é inferior ao número total de declarantes, porque há pessoas que são obrigadas a declarar, mas não têm renda suficiente para serem contribuintes do IRPF. Veja, por exemplo, a Tabela 2 para o ano-calendário de 1998, em que mais de 6 milhões de declarantes são isentos.

Tabela 2 - IRPF e pessoas ocupadas - ano-base 1998

\begin{tabular}{lccc}
\hline Faixa de Cálculo de IR & Pessoas Ocupadas ${ }^{(1)}(\mathrm{mil})$ & $\begin{array}{c}\text { Declarações } \\
\text { Entregues (mil) }\end{array}$ & $\begin{array}{c}\text { Contribuintes com } \\
\text { IR devido (mil) }\end{array}$ \\
\hline Até $\mathrm{R} \$ 10.800$ & 59.049 & 6.681 & 0 \\
De $\mathrm{R} \$ 10.800$ a $\mathrm{R} \$ 21.600$ & 6.496 & 2.623 & 2.623 \\
Acima de $\mathrm{R} \$ 21.600$ & 4.172 & 1.751 & 1.751 \\
\hline Total & 69.717 & 11.056 & 4.374 \\
\hline
\end{tabular}

Fonte: SRF e IBGE/PNAD 1999.

Nota: (1) Foi feita uma aproximação linear para as faixas de IR tomando-se como base a PEA e as Pessoas Ocupadas.

É importante ressaltar que esses baixos valores para as probabilidades representariam níveis de evasão artificialmente altos no modelo aqui proposto. Vários autores já lidaram com esse paradoxo e alguns (Erard; Feinstein, 1994, por exemplo) argumentaram que isso pode estar relacionado ao fato de que os contribuintes não têm uma idéia bastante clara de quais são realmente as probabilidades de auditoria que eles enfrentam, enquanto outros (Karni; Safra, 1990) acreditam que os indivíduos simplesmente as superestimam.

Para resolver este problema, adotar-se-á uma função utilidade esperada com probabilidades do tipo "rank dependent" (EURDP), conforme definida por Bernasconi (1998), que implica substituir $\mathrm{p}_{\mathrm{i}}$ por uma função, $f\left(\mathrm{p}_{\mathrm{i}}\right)$, contínua e estritamente crescente. Baseando-se em Camerer e Ho (1994), Bernasconni (1998) propõe a seguinte função:

$$
f(p)=1-\frac{(1-p)^{\gamma}}{\left[p^{\gamma}+(1-p)^{\gamma}\right]^{1 / \gamma}}, \quad \gamma=0.56
$$

O valor de 0,56 para $\boldsymbol{\gamma}$ foi determinado por Camerer e Ho (1994) que, tomando por base um grande conjunto de dados de experimentos conduzidos por pesquisadores em diversas partes do mundo, estimaram um modelo de melhor ajuste para um agente representativo e encontraram um ponto de igualdade da função definida acima, $\boldsymbol{f}(\boldsymbol{p})=\boldsymbol{p}$, próximo de $\mathbf{p}=0,7$. Ou seja, para $\mathbf{p}>0,7$ os indivíduos subestimariam as probabilidades e para $\mathbf{p}<0,7$ eles as superestimariam.

No presente caso, o indivíduo superestima $\mathbf{p}_{\mathrm{i}}$, dado que $\boldsymbol{f}\left(\mathbf{p}_{\mathrm{i}}\right) \geq \mathbf{p}_{\mathrm{i}}$. Assim, substituindo em (18) os valores de $\mathbf{p}_{1}, \mathbf{p}_{2}$ e $\mathbf{p}_{3}$ acima determinados, obtêm-se as seguintes probabilidades transformadas: $f\left(\mathbf{p}_{1}\right)=0,2781, \boldsymbol{f}\left(\mathbf{p}_{2}\right)=0,0488$ e $\boldsymbol{f}\left(\mathbf{p}_{3}\right)=0,1450$. 
c) Para a alíquota do IRPF será adotada a alíquota média de $\mathbf{t}=10,32 \%$, calculada para 1998 na forma apresentada na Tabela 1 .

d) As multas ${ }^{23}$ serão fixadas em $\boldsymbol{\theta}_{1}=1,5$ e $\boldsymbol{\theta}_{2}=3,0$.

e) Em relação aos 10.309 contribuintes fiscalizados após caírem em malha, foi lançado um crédito tributário adicional de $\mathrm{R} \$ 92.887 .930,00$. O valor inicialmente lançado por meio da revisão de MALHA foi de R $\$ 212.664 .470,00$. Assim, no ano de 1998, a revisão de MALHA detectou $0,696[=212.664 .470 /(212.664 .470+92.887 .930)]$ da evasão total cometida por esses contribuintes. Extrapolando este resultado para o conjunto total de contribuintes, pode-se adotar um valor inicial para a eficiência da malha de $\boldsymbol{\alpha}=70 \%$.

f) A renda tributável é normalizada em $\mathbf{R}=1$ e I é calculado em 1.3333, levando-se em consideração que, em média, as deduções correspondem a $25 \%$ da renda bruta (I), conforme se pode verificar a partir dos dados da Tabela 1.

\subsubsection{Resultados nacionais}

Passa-se, então, à análise das respostas da variável de decisão do contribuinte a mudanças nos parâmetros de imposição. Os resultados principais são apresentados nos gráficos a seguir e resumidos na Tabela 3. Os demais gráficos estão apresentados no Apêndice 2.

\section{Reação Ótima à Variação da Alíquota}

Inicialmente, observa-se como a renda declarada responde às mudanças nas alíquotas para três níveis de probabilidade de detecção em malha:

Figura 2 - Gráfico da renda declarada em função da alíquota de $\mathrm{t}$ - para três níveis de $\mathrm{p}_{1}$

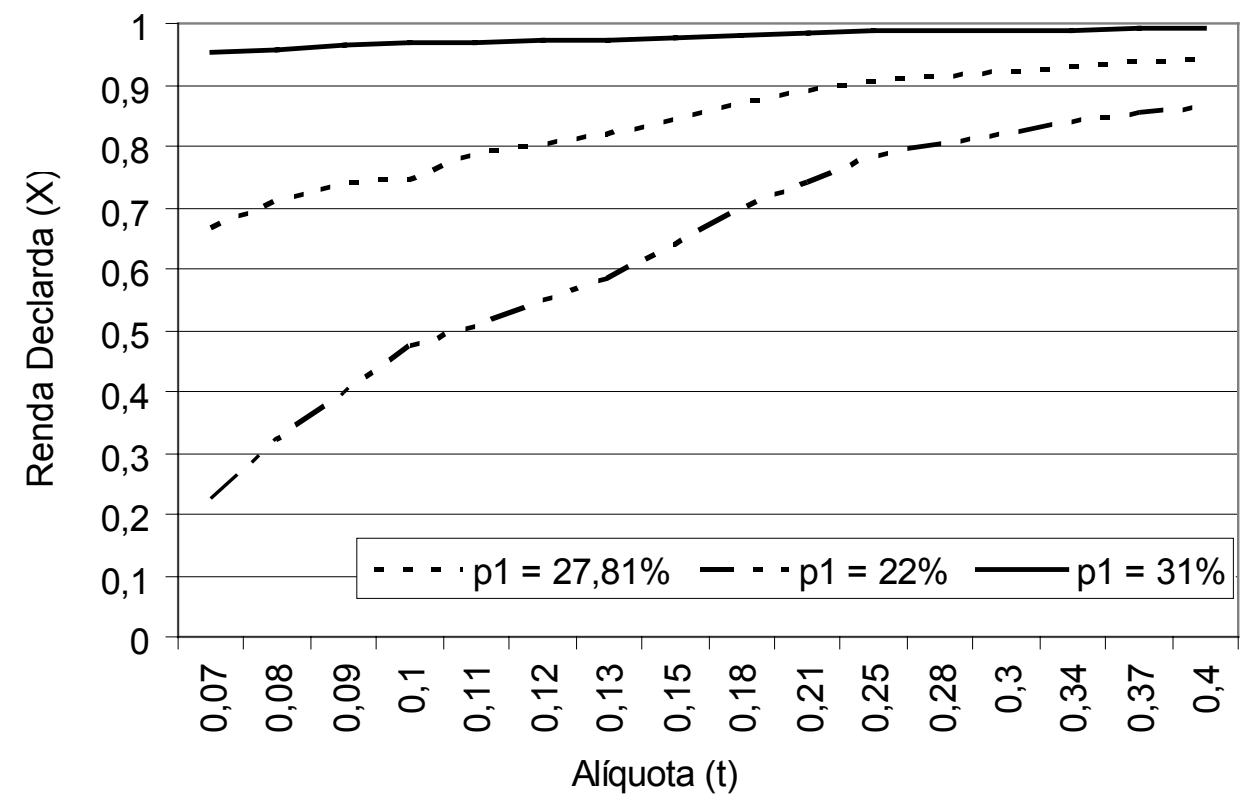

23 Decidiu-se calibrar as multas num valor um pouco mais alto que o estabelecido em lei, já que não há qualquer impedimento para que as infrações se acumulem e, além disso, como os créditos tributários são atualizados pela taxa SELIC, o valor da penalidade total (multa e juros) acaba sendo bem superior ao valor original legalmente estabelecido. 


\section{Reação Ótima à Variação da Penalidade}

Na Figura 3 observa-se como a renda declarada responde às mudanças na multa de malha $\left(\boldsymbol{\theta}_{1}\right)$ para três níveis de alíquota do imposto:

Figura 3 - Gráfico da renda declarada em função da multa de $\theta_{1}$ - para três níveis de $t$

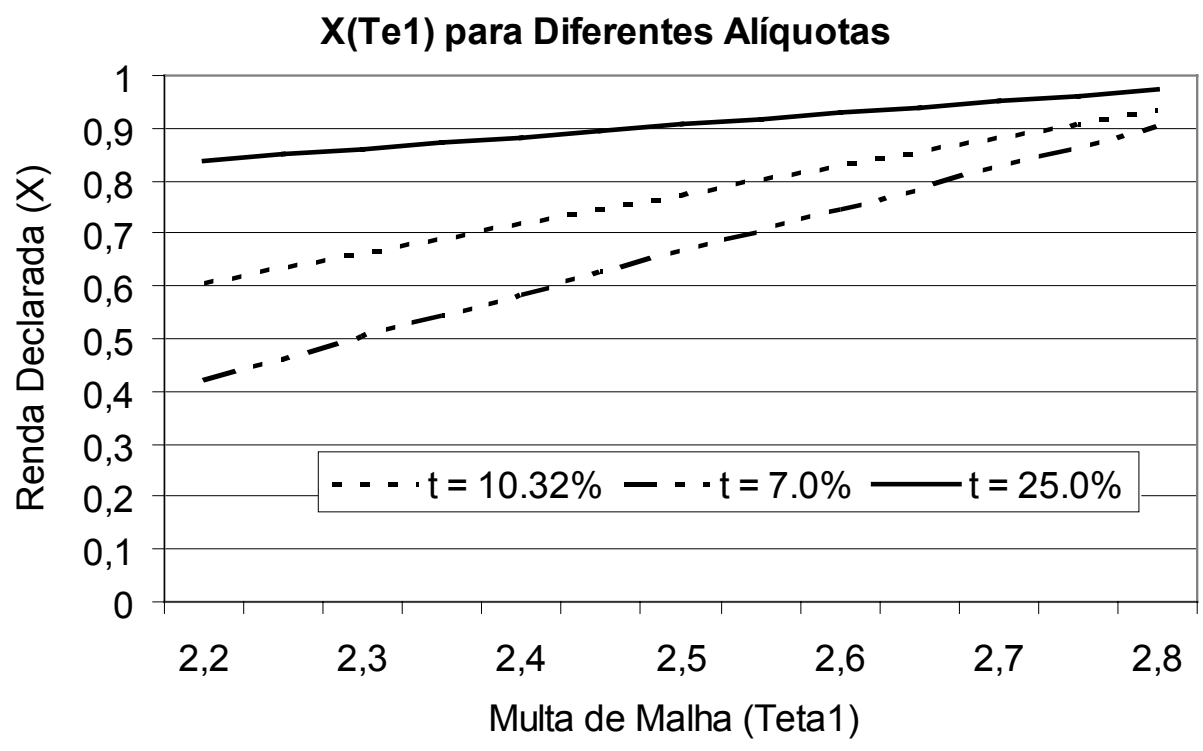

Em relação a variações em $\boldsymbol{\theta}_{2}$, observa-se a seguir como a renda declarada responde, dados os três níveis de multa de malha $\left(\boldsymbol{\theta}_{1}\right)$.

Figura 4 - Gráfico da renda declarada em função da multa de $\boldsymbol{\theta}_{2}$ - para três níveis de $\boldsymbol{\theta}_{1}$

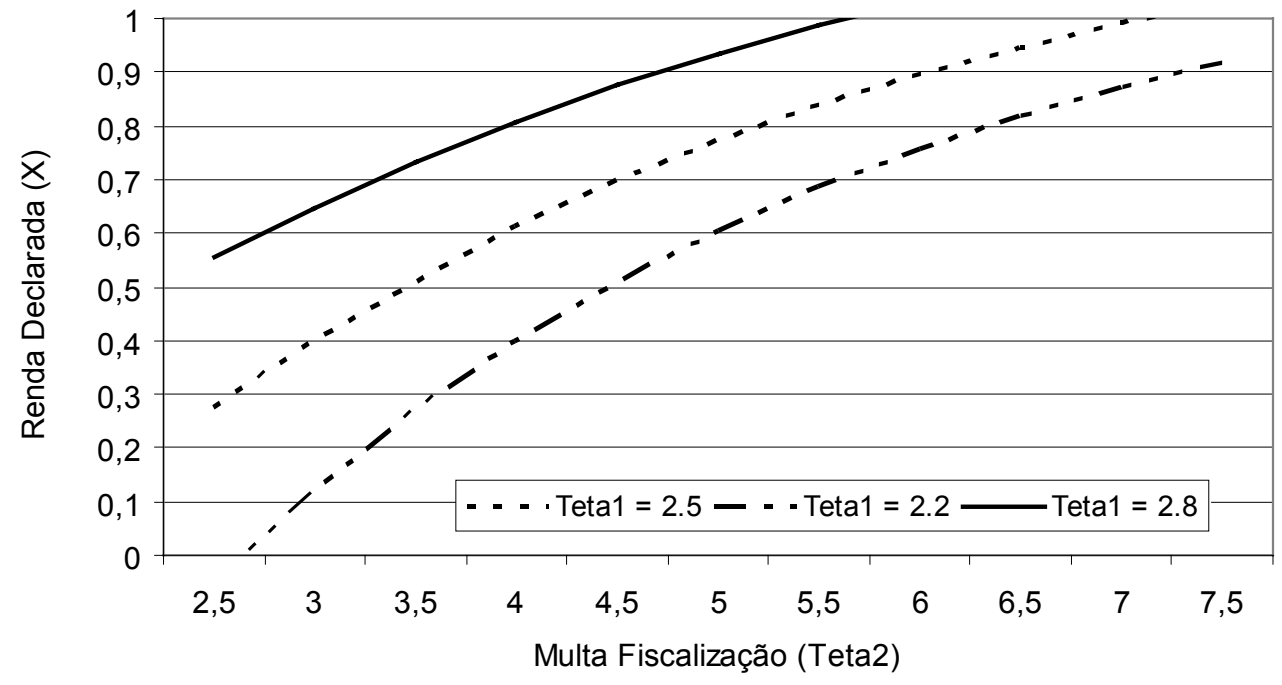




\section{Reação Ótima à Variação das Probabilidades}

$\mathrm{Na}$ Figura 5 pode ser observado como a renda declarada responde a variações em $\mathbf{p}_{1}$, dados quatro níveis de eficiência de malha $(\boldsymbol{\alpha})$ :

Figura 5 - Gráfico da renda declarada em função da probabilidade de detecção pela MALHA( $\left.p_{1}\right)$ - para quatro níveis de $\alpha$

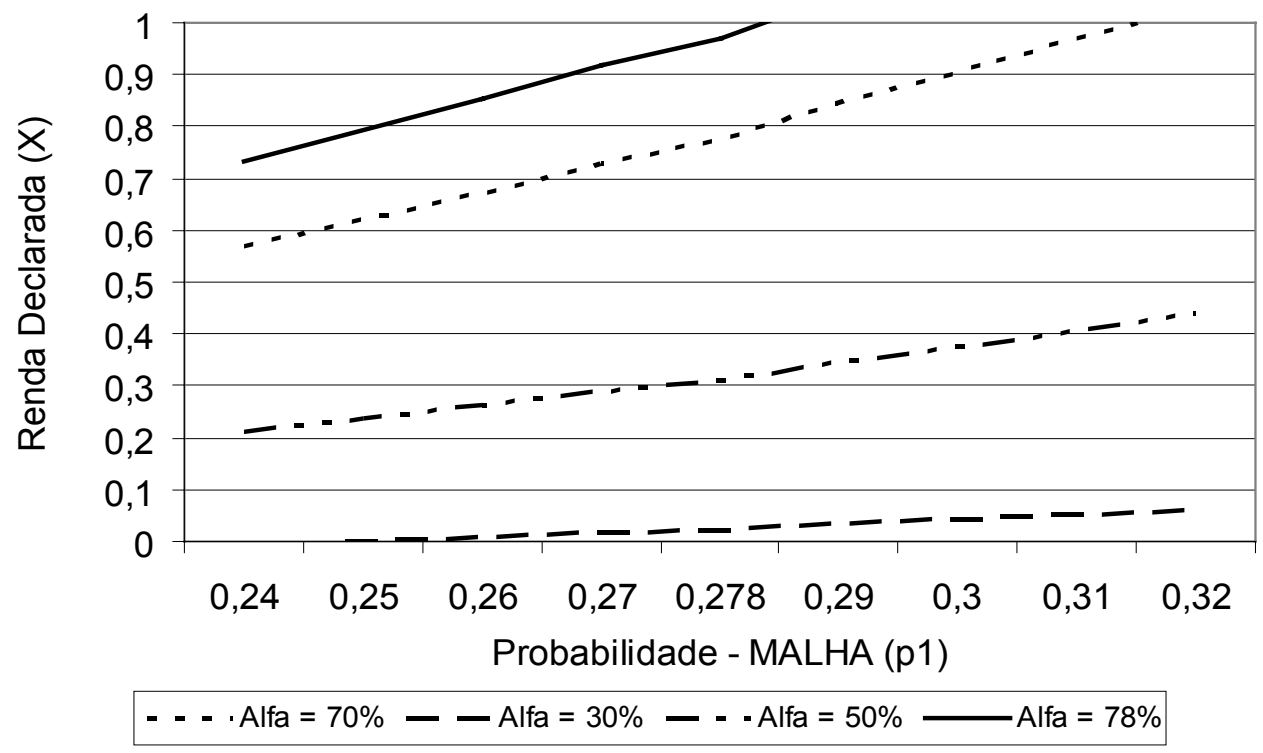

\section{Reação Ótima à Variação da Eficiência da Malha}

A Figura 6 mostra como a renda declarada responde a variações em $\boldsymbol{\alpha}$, dados três níveis da multa qualificada $\left(\boldsymbol{\theta}_{2}\right)$ :

Figura 6 - Gráfico da renda declarada em função eficiência da malha $(\alpha)$ - para três níveis de $\theta_{2}$

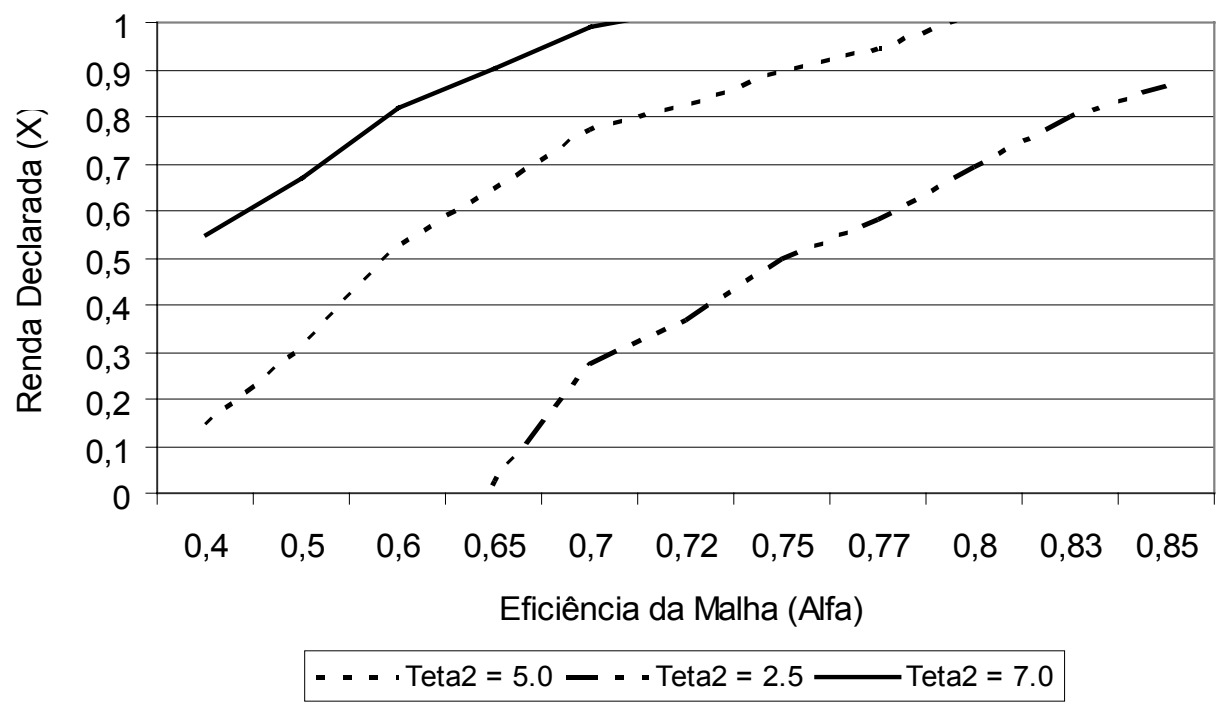




\section{Reação Ótima à Variação da Aversão ao Risco}

Embora tenha sido estabelecido no modelo original que o coeficiente de aversão relativa ao risco $(\boldsymbol{\beta})$ era constante, resolveu-se analisar como a renda declarada responde a variações em $\boldsymbol{\beta}$, dados três níveis de alíquota (t). A Figura 7 ilustra tal comportamento:

Figura 7 - Gráfico da renda declarada em da aversão ao risco $(\beta)$ - para três alíquotas

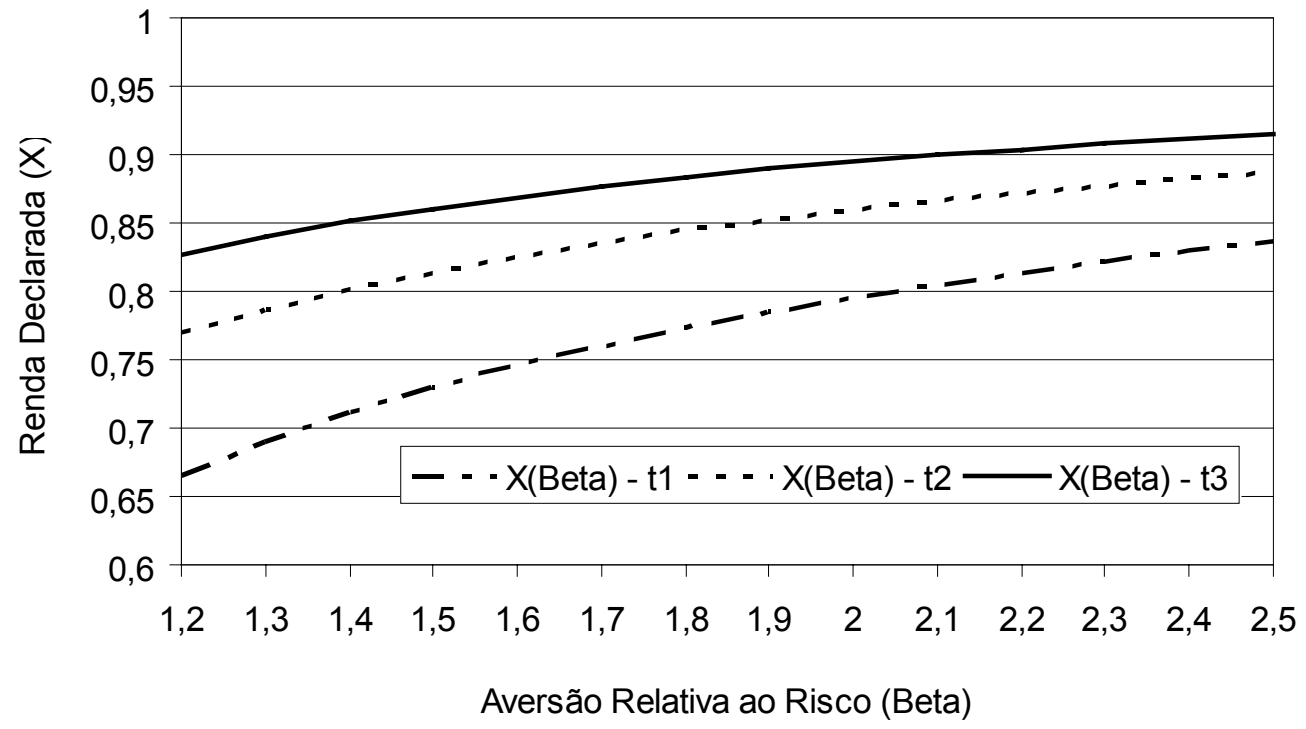

Tabela 3 - Resultados das simulações do modelo

( $\Omega$ Efeitos da Variação de $\Omega$ sobre a $\quad$ Efeitos Adicionais dos demais Outras Observações Importantes
Evasão $(\mathrm{dX} / \mathrm{d} \Omega) \quad$ Parâmetros

t A renda declarada cresce com a alíquota Um aumento individual em todos os Para altas alíquotas, um aumento nos (t), mas tal crescimento se dá a taxas parâmetros (mantidos os demais fixos) demais parâmetros do modelo não tem relativamente decrescentes. Apenas no não altera o sinal de $\mathbf{d X / d t}$, mas reduz grandes efeitos sobre a renda declarada; caso de baixa eficiência de malha ( $\alpha$ a renda marginal declarada; para altos na faixa de variação estudada $(7,0 \%<$ = 30\%) ou de baixa probabilidade de valores dos parâmetros de imposição $t<40 \%$ ), somente grandes variações fiscalização $\left(\boldsymbol{p}_{2}=1,0 \%\right)$ é que se pode $\left(\mathbf{p}_{1}=31 \%, \mathbf{p}_{2}=6,5 \%, \alpha=78 \%, \theta_{1}=2,8\right.$ em $\alpha, \theta_{2}$ e $\mathbf{p}_{2}$ têm efeito significativo se observar, para a faixa inicial de variação e $\left.\theta_{2}=7,0\right)$ o contribuinte já declara quase a alíquota já é superior a $37 \%$. Neste da alíquota, uma taxa de crescimento $100 \%$ de sua renda, independentemente caso, variações em $\theta_{1}$ e $\mathbf{p}_{1}$ alteram muito positiva. da alíquota a que é submetida a sua pouco a obediência tributária. renda.

$\theta_{1}$ A renda declarada cresce com a multa Constata-se, também, que aumentos Para $\theta_{1}$ superior a 2,8 um aumento sobre a evasão detectada na revisão nos demais parâmetros de imposição na alíquota $(\mathbf{t})$ não terá praticamente de malha $\left(\theta_{1}\right)$. 0 crescimento é linear. não alteram 0 sinal de $\mathbf{d X} / \mathbf{d} \theta_{1}$, pelo qualquer efeito sobre a renda À medida que os parâmetros $\alpha$ e $\mathbf{p}_{1}$ menos na faixa de variação estudada declarada, mas a variação nos demais aumentam, a taxa de crescimento tende $\left(2,2<\theta_{1}<2,8\right)$. parâmetros do modelo ainda tem efeitos a se acentuar, enquanto aumentos nos parâmetros $\mathbf{t}, \theta_{2}$ e $\mathbf{p}_{2}$ tendem a reduzisignificativos. la. 


\begin{tabular}{|c|c|}
\hline$(\Omega)$ & $\begin{array}{l}\text { Efeitos da Variação de } \Omega \text { sobre a } \\
\qquad \text { Evasão }(d X / d \Omega)\end{array}$ \\
\hline$\theta_{2}$ & $\begin{array}{l}\text { A renda declarada cresce com a multa } \\
\text { sobre a evasão detectada na fiscalização } \\
\left(\theta_{2}\right) \text {, mas a taxas decrescentes. }\end{array}$ \\
\hline $\mathbf{p}_{1}$ & $\begin{array}{l}\text { A renda declarada cresce com a } \\
\text { probabilidade de detecção da evasão na } \\
\text { auditoria interna }\left(\mathbf{p}_{1}\right) \text {. O crescimento se } \\
\text { dá a uma certa taxa fixa até } \mathbf{p}_{1}=0,28 \\
\text { aproximadamente, e a partir daí há um } \\
\text { aumento da referida taxa, indicando uma } \\
\text { mudança de comportamento quando as } \\
\text { probabilidades estão na faixa superior } \\
\text { de variação. }\end{array}$ \\
\hline
\end{tabular}

$\mathbf{p}_{2} \quad$ A renda declarada cresce com a probabilidade de a evasão ser detectada na fiscalização $\left(\mathbf{p}_{2}\right)$ a taxas relativamente constantes. $\alpha \quad$ A renda declarada cresce com a
eficiência da malha ( $\alpha)$, mas a taxas
relativamente decrescentes.
Efeitos Adicionais dos demais Parâmetros

Outras Observações Importantes
Um aumento nos demais parâmetros não altera o sinal de $\mathbf{d X} / \mathbf{d} \theta_{2}$. É bastante evidente a ocorrência de uma redução da taxa de crescimento à medida que $a$ alíquota (t) aumenta.

Para $\theta_{2}>7$ um aumento na alíquota ( $\mathbf{t}$ ) já não tem praticamente qualquer efeito sobre a renda declarada, mas variações nos demais parâmetros do modelo ainda têm efeitos significativos sobre a evasão fiscal.

Observa-se, também, que um aumento Para $\mathbf{p}_{1}>31 \%$ um aumento na alíquota nos parâmetros de imposição $\left(\alpha, \mathbf{t}, \theta_{2}\right.$, (t) já não tem praticamente qualquer $\left.\theta_{1}, p_{2}\right)$ não altera o sinal de $d X / d p_{1}$. efeito sobre a renda declarada, mas variações nos demais parâmetros do modelo ainda têm efeitos muito significativos.

Um aumento nos parâmetros de imposição $\left(\alpha, \mathbf{t}, \theta_{1}, \mathbf{p}_{1}\right.$ e $\left.\theta_{2}\right)$ não altera

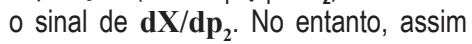
como no caso de $\theta_{2}$, fica também evidente a ocorrência de uma redução da taxa de crescimento à medida que $\mathbf{t}$

aumenta.

Para $\mathbf{p}_{2}>6,5 \%$ um aumento na alíquota (t) já não tem praticamente qualquer efeito sobre a renda declarada, mas variações nos demais parâmetros do modelo ainda têm efeitos muito significativos.

Um aumento nos parâmetros $\mathbf{t}, \theta_{1}, \theta_{2}$ Para $\alpha>80 \%$ um aumento na alíquota $, \mathbf{p}_{1}, \mathbf{p}_{2}$ não altera o sinal de $\mathbf{d X} / \mathbf{d} \alpha$. ( $\mathbf{t}$ ) já não tem praticamente qualquer Observa-se, também, que aumentos efeito sobre a renda declarada, pois 0 em $\mathbf{t}$ tendem a reduzir a renda marginal contribuinte já tende a declarar $100 \%$ declarada, enquanto aumentos em $\theta_{1}$ e de sua renda tributável. No entanto, $\mathbf{p}_{1}$ a aumentam. Variações em $\theta_{2}$ e $\mathbf{p}_{2}$, variações nos demais parâmetros do no entanto, não deixa evidente qualquer modelo ainda têm efeitos significativos. mudança em relação à renda marginal declarada.

\subsubsection{Análise quantitativa dos efeitos das variações dos parâmetros sobre a renda declarada}

A fim de se obter respostas quantitativas referentes à variável de decisão do contribuinte (renda declarada), quando ocorrem mudanças nos parâmetros do modelo, promoveu-se uma variação de $5 \%$ em cada um destes, mantendo os demais constantes. Esse pequeno exercício quantitativo resultou nas seguintes variações porcentuais na renda declarada e correspondentes elasticidades:

Tabela 4 - Efeitos das variações dos parâmetros sobre a renda declarada

\begin{tabular}{lcccccccc}
\hline Parâmetro & $t$ & $p_{1}$ & $p_{2}$ & $p_{3}$ & $\theta_{1}$ & $\theta_{2}$ & $\alpha$ & $\beta$ \\
\hline$\Delta X(\%)$ & 5,38 & 8,47 & 6,59 & 10,32 & 13,17 & 8,60 & 15,73 & 1,36 \\
Elasticidade $(\varepsilon)$ & 1,076 & 1,694 & 1,318 & 2,063 & 2,634 & 1,72 & 3,146 & 0,272 \\
\hline
\end{tabular}

Fonte: Elaboração do autor.

Uma análise superficial da tabela acima mostra que aumentar determinados parâmetros tem maiores efeitos sobre a obediência tributária do que aumentos em outros. A ordem decrescente de 
resposta é dada por $\varepsilon_{\alpha}>\varepsilon_{\theta 1}>\varepsilon_{\mathrm{p} 3}>\varepsilon_{\theta 2}>\varepsilon_{\mathrm{p} 1}>\varepsilon_{\mathrm{p} 2}>\varepsilon_{\mathrm{t}}$, ou seja, aumentar a eficiência da malha ( $\left.\alpha\right)$ é mais eficiente do que aumentar a multa de MALHA $\left(\theta_{1}\right)$, que é mais eficiente do que aumentar a probabilidade de FISCALIZAÇÃO $\left(\mathbf{p}_{3}\right)$, e assim por diante. Observa-se, também, que à exceção do resultado à variação na aversão relativa ao risco $(\boldsymbol{\beta})$, todas as respostas são elásticas.

Cabe à autoridade tributária, portanto, avaliar os custos de cada uma dessas políticas e definir qual delas deve ser preferencialmente adotada ou, até mesmo, se a adoção de uma combinação delas não traria resultados mais significativos em termos de política de combate à evasão fiscal.

Especificamente no caso da aversão relativa ao risco ( $\boldsymbol{\beta})$, os resultados estão consistentes com a teoria, ou seja, maior aversão ao risco implica menor evasão.

Para melhor visualizar os efeitos de mudanças no valor da aversão relativa ao risco $(\boldsymbol{\beta})$ sobre os resultados anteriormente encontrados, apresenta-se, na Figura 8 a seguir, uma análise de sensibilidade, na qual a trajetória da renda declarada como função das alíquotas do imposto é traçada para três níveis distintos de $\boldsymbol{\beta}{ }^{24} \mathrm{O}$ que se constata é que quanto maior o seu valor, maior é a renda declarada (ou seja, menor é a evasão), sendo que para altas alíquotas o efeito da aversão relativa ao risco é minimizado.

Figura 8 - Gráfico da renda declarada em função da alíquota $t$ - para três níveis de aversão relativa ao risco $(\beta)$

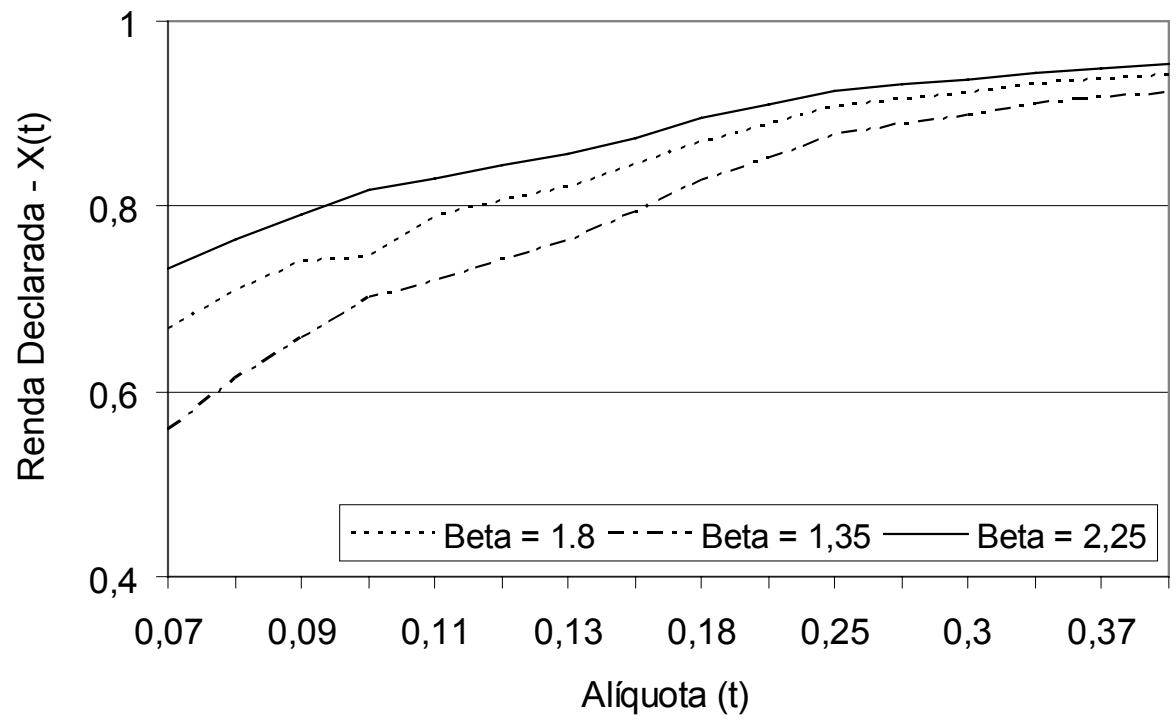

Após ter analisado o comportamento individual do contribuinte do IRPF em seu aspecto global (nacional), algumas questões complementares ao tema ora em estudo não poderiam ser deixadas de lado: haverá diferenças nas reações dos contribuintes se se considerar algum tipo de desagregação destes em determinados subgrupos? Se houver (o que parece bastante provável ${ }^{25}$ ), seria o modelo aqui desenvolvido capaz de captar tais diferenças? As evidências empíricas (se houver), por sua vez, corroborariam os resultados do modelo?

24 É importante ressaltar que pequenas variações em $\boldsymbol{\beta}$ (menores que 10\%) praticamente não alteram os resultados do modelo. Para que os resultados sofram alterações relevantes é necessário que $\boldsymbol{\beta}$ varie intensamente. Na Figura 8, variou-se o $\boldsymbol{\beta}$ inicial de $1.8 \mathrm{em} 25 \%$, para mais $(2.25)$ e para menos $(1,35)$.

25 Ver, por exemplo, Scotchmer (1987), Feinstein (1991) e Franzoni (1999). 
Para tentar responder a questões dessa natureza, os dados nacionais serão desagregados - em função da sua disponibilidade e sem que seja necessário adotar hipóteses pouco realistas ou extremamente restritivas - por Regiões Geográficas.

\subsection{Análise desagregada por regiões geográficas}

Para esta análise, os dados dos contribuintes serão divididos pelas cinco Regiões Geográficas do Brasil (Norte, Nordeste, Centro-Oeste, Sudeste e Sul). A Tabela 5, adiante, fornece todos os dados necessários à realização das simulações e das comparações empíricas para o ano de 1998 (exercício de 1999).

\subsubsection{Calibragem do modelo}

Da mesma forma que na simulação com dados globais (nacionais), os totais de contribuintes por região foram estimados com base nos indivíduos da População Economicamente Ativa (PEA) que ganham mais de 5 salários mínimos em cada uma das regiões do País. O número de declarantes foi obtido na SRF. A variável "Incidência em Malha" corresponde ao total de declarações que foram retidas na malha fina da SRF para análise interna e foram obtidas também na base de dados da SRF. Tais dados podem ser consultados nos relatórios de gestão da SRF, que embora sejam desagregados por Regiões Fiscais (RF), podem facilmente ser convertidos em dados regionais. ${ }^{26}$

O total de contribuintes fiscalizados (diretamente e após análise da malha) e os créditos tributários gerados também foram obtidos com a autoridade tributária brasileira e podem ser consultados na sua página na internet (www.receita.fazenda.gov.br).

É importante deixar registrado que os créditos tributários gerados na atividade de fiscalização compreendem tanto o imposto que não foi voluntariamente pago quanto a multa incidente sobre esta parcela do imposto.

De posse dos dados até aqui explicitados, é possível calcular as probabilidades de auditoria interna $\left(\mathbf{p}_{1}=\right.$ Probabilidade de Malha $)$ e de fiscalização externa $\left(\mathbf{p}_{2}=\right.$ Probabilidade de Fiscalização/não malha e $\mathbf{p}_{3}=$ Probabilidade de Fiscalização/malha) por meio das relações definidas em (17). A partir dessas probabilidades, calculam-se as probabilidades efetivas, conforme especificado por Bernasconi (1998), via equação (18).

Antes de adentrar na enunciação das hipóteses para calibragem e simulação dos respectivos modelos é necessário tratar de uma questão secundária, mas não menos importante: quais serão os dados empíricos que servirão de base para a validação dos resultados obtidos? Existe alguma medida de evasão do IRPF desagregada por Regiões? Infelizmente a resposta é não! Como resolver, então, este problema?

Neste momento só é possível vislumbrar uma maneira: criar uma medida de evasão específica para o presente caso, que, mesmo de forma aproximada, possa servir como parâmetro de teste para o modelo. É o que se passa a discutir.

Após perscrutar a base de dados da SRF em busca de elementos que permitissem construir uma medida de evasão desagregada por regiões, optou-se por utilizar os dados das declarações de rendimentos, em conjunto com aqueles referentes aos contribuintes fiscalizados, de uma forma semelhante ao sugerido por Clotfelter (1983). Foram, então, seguidos os seguintes procedimentos:

26 O Centro-Oeste corresponde à $1^{\mathrm{a}} \mathrm{RF}$, o Norte à $2^{\mathrm{a}} \mathrm{RF}$, o Nordeste às $3^{\mathrm{a}}, 4^{\mathrm{a}}$ e $5^{\mathrm{a}} \mathrm{RF}$, o Sudeste às $6^{\mathrm{a}}, 7^{\mathrm{a}}$ e $8^{\mathrm{a}} \mathrm{RF}$ e o Sul às $9^{\mathrm{a}}$ e $10^{\mathrm{a}}$ RF. 
i) com os dados das declarações de rendimentos, obteve-se a renda total declarada e o total de declarantes por região. Assim, foi possível determinar a renda declarada média (individual), apresentada na $11^{\mathrm{a}}$ linha da Tabela 5;

ii) com os dados dos contribuintes fiscalizados, obteve-se o crédito tributário médio gerado por contribuinte (individual), dado pela relação entre o crédito tributário total e o número de contribuintes fiscalizados. A partir desse valor, e supondo que todos os contribuintes fiscalizados tenham sido tributados à alíquota de $27,5 \%$ e tenham incorrido em multa de $75 \%,{ }^{27}$ pôde-se determinar a renda verdadeira média desses contribuintes, a partir da seguinte expressão:

$$
R M V=R M D+\frac{C C F}{(1+0,75) \cdot 0,275}
$$

em que RMV é a renda média verdadeira, RMD é a renda média declarada e CCF é o crédito tributário por contribuinte fiscalizado;

iii) de posse da RMD e da RMV, é possível obter o porcentual declarado da renda verdadeira e, com isso, determinar o porcentual de evasão em cada Região Geográfica. Tais valores estão todos apresentados na Tabela 5.

Tabela 5 - Variáveis desagregadas por regiões geográficas

\begin{tabular}{lrrrrrr}
\hline Variáveis & $\mathrm{N}$ & $\mathrm{NE}$ & $\mathrm{CO}$ & \multicolumn{1}{c}{$\mathrm{SE}$} & \multicolumn{1}{c}{$\mathrm{S}$} & TOTAL \\
\hline $\mathrm{N}^{0}$ de contribuintes & 348.811 & 1.306 .432 & 749.811 & 6.257 .207 & 2.003 .789 & 10.666 .050 \\
$\mathrm{~N}^{0}$ de declarantes & 361.499 & 1.353 .954 & 777.086 & 6.484 .817 & 2.076 .678 & 11.054 .034 \\
Incidência em malha & 38.013 & 102.554 & 47.099 & 398.625 & 104.362 & 690.653 \\
Fiscalizados após a malha & 925 & 1.897 & 471 & 5.035 & 1.981 & 10.309 \\
Fiscalizados diretamente & 780 & 1.599 & 397 & 4.245 & 1.671 & 8.692 \\
Total de fiscalizados & 1.704 & 3.496 & 868 & 9.280 & 3.653 & 19.001 \\
Créditos gerados (em mil R\$) & $9.801,60$ & $25.783,80$ & $21.050,40$ & $220.588,80$ & $28.327,80$ & $305.552,40$ \\
Crédito/contribuinte fiscalizado em mil R\$) & 5,75 & 7,38 & 24,25 & 23,77 & 7,75 & 16,08 \\
Renda total declarada (em milhões de R\$) & $8.355,00$ & $32.176,00$ & $21.640,00$ & $200.486,00$ & $49.459,00$ & $312.116,00$ \\
Renda média declarada (em mil R\$) & 23,11 & 23,76 & 27,85 & 30,92 & 23,82 & 28,24 \\
Renda média verdadeira (em mil R\$) & 35,06 & 39,09 & 78,24 & 80,31 & 39,93 & 61,65 \\
Porcentual declarado (\%) & $65,91 \%$ & $60,79 \%$ & $35,59 \%$ & $38,50 \%$ & $59,65 \%$ & $45,80 \%$ \\
Evasão (\%) & $34,09 \%$ & $39,21 \%$ & $64,41 \%$ & $61,50 \%$ & $40,35 \%$ & $\mathbf{5 4 , 2 0 \%}$ \\
Probabilidade de malha & 0,1052 & 0,0757 & 0,0606 & 0,0615 & 0,0503 & 0,0625 \\
Probabilidade de fiscalização & 0,0049 & 0,0027 & 0,0012 & 0,0015 & 0,0018 & 0,0018 \\
\hline
\end{tabular}

Fonte: SRF.

Notas: Dados referentes ao ano de 1998 (IRPF - Exercício 1999).

Apesar de esses resultados sugerirem altos níveis de evasão, deve-se assinalar que a extrapolação dessa experiência para todo o universo de contribuintes deve ser considerada com cuidado, pois algumas limitações inerentes ao processo de seleção dos contribuintes devem ser analisadas, entre as quais podem ser citadas as seguintes:

1) o critério de seleção dos contribuintes pode estar viciado por indícios prévios de sonegação e até mesmo por denúncias, já que os resultados relativos à renda não-declarada se referem, tãosomente, aos contribuintes fiscalizados pela SRF;

27 Tais hipóteses são bastante realistas, haja vista que a grande maioria dos fiscalizados encontra-se nessa última faixa de alíquota e raramente são aplicadas multas agravadas (de 150\%). 
2) outra restrição que se enfrenta é que as estimativas baseadas em dados da SRF relacionam-se somente aos declarantes, não trazendo quaisquer informações sobre os não-declarantes. Conforme observou Franzoni (1999), os não-declarantes são parte importante da atividade sonegadora e desconsiderá-los pode enviesar tais estimativas;

3) sabe-se que as auditorias fiscais têm uma capacidade limitada de detectar a evasão, especialmente em relação às rendas dos autônomos e daqueles que realizam somente operações em dinheiro; assim, em alguns casos, os valores evadidos podem ser um pouco maiores que os estimados com base somente nas auditorias;

4) por último, deve ser ressaltado que estudos baseados em pesquisas amostrais enfrentam diversos problemas. Entre eles, o mais importante é que os resultados dependem crucialmente da representatividade da amostra e de eventuais vieses de seleção.

Dessa forma, ao apresentar valores de evasão obtidos com base em metodologias semelhantes a que aqui foi proposta, deve-se ficar alerta para as limitações que tal metodologia impõe aos respectivos resultados.

Em relação às demais hipóteses de calibragem, optar-se-á pela mesma função utilidade isoelástica, definida pela equação (15), agora para a utilidade do contribuinte de cada região. Conseqüentemente, supôs-se que não há diferenças de avaliação de bem-estar pelos indivíduos entre regiões. ${ }^{28}$

Como a tributação do IRPF é definida em bases nacionais, as variáveis de imposição também serão as mesmas para todas as regiões, ou seja: $\mathbf{t}=10,32 \%, \theta_{1}=1,5$ e $\theta_{2}=3,0$. Admitir-se-á, também, que a eficiência da malha não varia entre regiões e é igual a 70\%. Da mesma forma que no caso agregado, a renda tributável é normalizada em $\mathbf{R}=1$ e $\mathbf{I}=1.3333$.

Se não há diferenças nas variáveis de imposição e nem na avaliação da utilidade da renda, como pode haver diferenças de comportamento dos indivíduos em função da região em que vive? A resposta está na percepção do risco, ou seja, nas efetivas probabilidades de detecção da infração. Logo, as diferentes probabilidades apresentadas na Tabela 5 é que determinarão o comportamento diferenciado dos indivíduos em cada região.

Feitas essas considerações, o que o modelo aqui desenvolvido pode fornecer de respostas ou indícios? Será que suas respostas encontram eco nas evidências empíricas aqui apresentadas? É o que se passa a analisar.

A Figura 9, a seguir, apresenta os resultados da simulação, em que a renda declarada (X) é função da Alíquota (t) do imposto e cada região apresenta uma trajetória específica.

Conforme se pode observar, consideradas as hipóteses precedentes, o modelo conclui que, independentemente da alíquota adotada, os contribuintes do Norte é que apresentariam maiores graus de obediência tributária (menor evasão), sendo seguidos pelos do Nordeste, do Sul, do Sudeste e do Centro-Oeste, nesta ordem.

Para uma alíquota de 27,5\% (alíquota adotada no cálculo da evasão em cada região), os valores porcentuais de evasão fornecidos pelo modelo seriam de: $\mathrm{N}=15,95 \%, \mathrm{NE}=38,9 \%, \mathrm{~S}=55,28 \%$, $\mathrm{SE}=56,03 \%$ e $\mathrm{CO}=61,24 \%$.

Se tais valores forem comparados com os valores empíricos anteriormente obtidos $(\mathrm{N}=$ $34,09 \%, \mathrm{NE}=39,21 \%, \mathrm{~S}=40,37 \%, \mathrm{SE}=61,50 \%$ e $\mathrm{CO}=64,41 \%$ ), pode-se concluir que: (1) o modelo apresenta uma ordem de classificação semelhante à dos resultados empíricos $\left(1^{\circ}-\mathrm{CO}, 2^{\circ}\right.$

28 Uma sugestão de refinamento do modelo para estudos futuros seria a realização de pesquisas regionais que determinassem os diferentes $\boldsymbol{\beta}$ da função isoelástica aqui considerada para cada uma das regiões ou grupos econômicos que se desejasse analisar. 
- SE, $3^{\circ}-\mathrm{S}, 4^{\circ}-\mathrm{NE}$ e $5^{\circ}-\mathrm{N}$ ); (2) à exceção das regiões Sul e Norte, os porcentuais obtidos também foram semelhantes, com discrepâncias de menos de $5 \%$ em valores absolutos.

Figura 9 - Gráfico da renda declarada em função de t para diferentes regiões geográficas

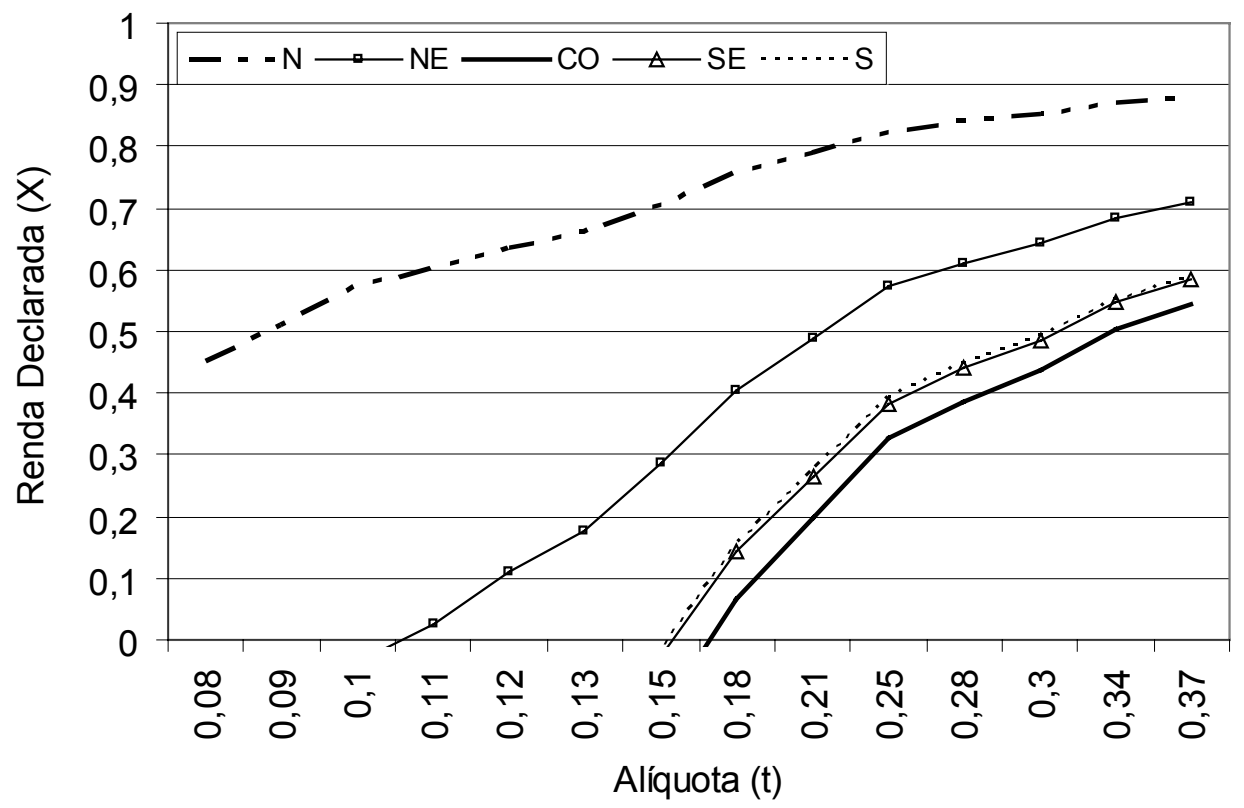

Em outras palavras, o modelo capta bem as diferenças regionais de comportamento, demonstrando que os contribuintes das cinco regiões avaliam de forma diferente os riscos da atividade de sonegação, parecendo perceber corretamente as diferentes probabilidades de detecção. Nas conclusões e considerações finais, discutir-se-ão quais são as implicações desses resultados para o desenho do esquema de auditoria.

\section{CONCLUSÕES E CONSIDERAÇÕES FINAIS}

O problema da sonegação fiscal é tão antigo quanto os impostos em si. Embora seja comum afirmar que as únicas coisas certas na vida sejam a morte e os impostos, não há dúvidas de que quase sempre há uma forma de se evitar estes últimos, ou pelo menos parte deles. Como os indivíduos, em geral, não gostam de pagar impostos, farão tudo o que puderem para reduzi-los.

O modelo desenvolvido neste artigo, baseado numa extensão do modelo seminal de Allingham e Sandmo (1972), no qual foram introduzidas outras variáveis de imposição e fiscalização, sugere que:

1) um aumento nas probabilidades de detecção da infração (tanto na auditoria interna - MALHA - quanto na externa - FISCALIZAÇÃO) e nas penalidades (simples ou agravada) reduzem a evasão do imposto sobre a renda da pessoa física, resultado semelhante à previsão inicial de Allingham e Sandmo (1972);

2) um aumento da alíquota marginal do imposto também reduz a evasão, contrariando a observação de Yitzhaki (1974) de que não haveria qualquer relação entre a alíquota do imposto e a evasão fiscal, mas indo ao encontro das evidências obtidas por Wasilewski (2001) de que o 
aumento da alíquota marginal média teria sido acompanhado por uma redução na evasão no período 1996/1998;

3) um aumento na eficiência da deteç̧ão da MALHA reduz a sonegação, mostrando que trabalhar a eficiência da auditoria interna da SRF pode trazer resultados tão ou mais significativos que a modificação da estrutura de imposição (multas e probabilidades de detecção), normalmente difícil de ser implementada, por não se restringir ao âmbito de atuação legal da agência fiscalizadora;

4) da mesma forma, no que se refere aos resultados desagregados por região fiscal, o modelo permitiu que se chegasse à conclusão principal de que, independentemente da alíquota adotada, os contribuintes do Norte é que apresentaram maiores graus de obediência tributária (menor evasão, com cerca de apenas 3\%), sendo seguidos pelos do Nordeste (20\%), do Sul (31\%), do Sudeste (32\%) e do Centro-Oeste (36\%), nesta ordem.

No mesmo sentido, os resultados obtidos corroboraram as evidências empíricas, indicando que o modelo proposto capta bem as diferenças regionais de comportamento, demonstrando que os contribuintes das cinco regiões avaliam de forma diferente os riscos da atividade de sonegação.

Portanto, em razão dos custos de se adotar cada uma das políticas de imposição fiscal aqui apresentadas, dos efeitos marginais dessa adoção e das limitações legais quanto à respectiva implementação, ${ }^{29}$ a autoridade tributária pode traçar suas estratégias de combate à evasão fiscal.

Por outro lado, simulações do comportamento do contribuinte por meio do modelo aqui proposto e com dados mais recentes podem auxiliar a SRF na condução de suas estratégias de auditoria, trabalhando especificamente sobre os parâmetros que tenham maiores efeitos no combate da evasão fiscal e/ou sobre os contribuintes de regiões que parecem subdeclarar um maior porcentual das suas rendas tributáveis.

Além disso, o modelo apresentado forneceu valores para a evasão fiscal do IRPF bem próximos aos obtidos em trabalhos de mensuração indireta, sem a necessidade de que fossem adotadas hipóteses pouco realistas, como sugeridas por alguns pesquisadores. ${ }^{30}$ Em outras palavras, a extensão ao modelo de Allingham e Sandmo (1972) proposta neste artigo contribuiu para melhorar significativamente as respostas obtidas via simulações numéricas dos modelos de utilidade esperada utilizados nos estudos de obediência tributária.

Estudos posteriores poderão refinar ainda mais o modelo, adotando, por exemplo, outras funções de utilidade ou valores para aversão relativa ao risco específicas para o caso brasileiro ou, ainda, diferenciando os parâmetros de imposição entre as regiões. Pode-se, também, analisar outras desagregações (por categorias de contribuintes, por classes de renda etc). Tudo isto contribuiria, de forma significativa, para um melhor conhecimento do comportamento do contribuinte ante o sistema impositivo brasileiro, o que seria de grande relevância para o estabelecimento de novas estratégias de combate à evasão fiscal.

29 Embora aumentar multas não tenha, a princípio, qualquer custo para a Administração Tributária, limitações legais relativas à impossibilidade de que tais exações sejam consideradas confiscatórias impedem a utilização indiscriminada dessa política.

30 Alguns trabalhos que utilizaram o modelo de Allingham e Sandmo (1972) para simulações do comportamento real do contribuinte tiveram que adotar multas de $1.000 \%(\boldsymbol{\theta}=10)$ e/ou Aversão Relativa ao Risco $(\boldsymbol{\beta})$ igual a 20. Conforme observou Bernasconi (1998), tais valores são difíceis de sustentar numa modelagem econômica que pretenda simular o comportamento real dos agentes. 


\section{REFERÊNCIAS}

Allingham, Michael G.; Sandmo, Agnar. Income tax evasion: a theoretical analysis. Journal of Public Economics, Amsterdam, v. 1, p. 323-338, 1972.

Alm, James. Tax compliance and administration. Working Paper $n^{\circ}$ 98-12, Center for Economic Analysis, Department of Economics, Boulder: University of Colorado, 1998.

. Uncertain tax policies, individual behavior, and welfare. The American Economic Review, v. 78, p. 237-245, 1988.

Andreoni, James; Erard, Brian; Feinstein, Jonathan.S. Tax compliance. Journal of Economic Literature, Stanford, v. 36, p. 818-860, 1998.

BEA - Bureau of Economic Analysis Foundation. On personal income tax evasion in 1995 - 1997. Information Bulletin $n^{\circ}$ 6, Moscow, maio 1998.

Becker, Gary. Crime and punishment: an economic approach. Journal of Political Economy, Chicago, v. 76, p. 169-217, 1968.

Bernasconi, Michele. Tax evasion and orders of risk aversion. Journal of Public Economics, Amsterdam, v. 67, n. 1, p. 123-134, jan. 1998.

Camerer, Colin F.; Ho, Teck-Hua. Violations of the betweenness axiom and nonlinearity in probability. Journal of Risk and Uncertainty, v. 8, p. 167-196, 1994.

Clotfelter, Charles T. Tax evasion and tax rates: an analysis of individual returns. Review of Economics and Statistics, Cambridge, v. 65, p. 363-373, 1983.

Cowell, Frank A. Cheating the government: the economics of evasion. Cambridge, MA: MIT Press, 1990. $267 \mathrm{p}$.

. Taxation and labour supply with risky activities. Economica, v. 48, p. 365-379, 1981.

Cowell, Frank A.; Gordon, James P. F. Unwillingness to pay: tax evasion and public good provision. Journal of Public Economics, v. 36, p. 305-321, 1988.

Cross, Rodney B.; Shaw, Graham K. On the economics of tax aversion. Public Finance/Finances Publiques, v. 37, p. 36-47, 1982.

Elffers, Henk. Income tax evasion: theory and measurement. Kluwer: Deventer, 1991.

Epstein, Larry G. Behavior under risk: recent developments in theory and applications. In: Laffont, JeanJacques (ed.), Advances in economic theory: Sixth World Congress of The Econometric Society, v. II. Cambridge: Cambridge University Press, 1992, p. 1-63.

Erard, Brian; Feinstein, Jonathan S. The role of moral sentiments and audit perceptions in tax compliance. Public Finance/Finances Publiques, v. 49 (Supplement), p. 70-89, 1994.

Falkinger, Josef; Walther, Herbert. Rewards versus penalties: on a new policy against tax evasion. Public Finance Quarterly, v. 19, p. 67-79, 1991.

Feinstein, Jonathan S. An econometric analysis of income tax evasion and its detection. Rand Journal of Economics, Santa Mônica, v. 22, p. 14-35, 1991.

Franzoni, Luigi A. Tax evasion and tax compliance. Working Paper 6020, Italy: University of Bolonha, 1999.

Graetz, Michael J.; Wilde, Louis L. The economics of tax compliance: fact and fantasy. National Tax Journal, v. 38, p. 355-363, 1985.

Jorratt, Michael. An analysis of the Chilean tax system. Division of Studies, Servicio de Impuestos Internos, October 1998.

Kahneman, Daniel; Tversky, Amos. Prospect theory: an analysis of decision under Risk. Econometrica, v. 47, p. 263-291, 1979.

Karni, Edi; Safra, Zvi. Rank-dependent probabilities. Economic Journal, v. 100, p. 487-495, 1990. 
Karni, Edi; Schmeidler, David. Utility theory with uncertainty. In: Hildebrand, Werner; Sonnenschein, Hugo. (eds.), Handbook of mathematical economics. V. 4. Amsterdam: North Holland, 1990, p.17631831.

Kesselman, Jonathan R. Income tax evasion: an intersectoral analysis. Journal of Public Economics, v. 38, p. 137-182, 1989.

Long, Susan B.; Swingen, Judyth A. Taxpayer compliance: setting new agendas for research. Law and Society Review, v. 25, p. 637-683, 1991.

Pencavel, John H. A note on income tax evasion, labor supply, and nonlinear tax schedules. Journal of Public Economics, Amsterdam, v. 12, p. 115-124, 1979.

Pestieau, Pierre; Possen, Uri M. Tax evasion and occupational choice. Journal of Public Economics, v. 45, p. 107-125, 1991.

Pommerehne, Werner; Weck-Hannemann, Hannelore. Tax rates, tax administration and income tax evasion in Switzerland. Public Choice, v. 88, p. 161-70, 1996.

Reinganum, Jennifer F.; Wilde, Louis L. Equilibrium enforcement and compliance in the presence of tax practitioners. Journal of Law, Economics, and Organization, Oxford, v. 7, p. 163-181, 1991.

Roth, J.; Scholtz, J.; Witt A. Taxpayer compliance: an agenda for research. V. 1. Philadelphia: University of Pennsylvania Press, 1989.

Scotchmer, Suzanne. Audit classes and tax enforcement policy. American Economic Review, Princeton, v. 77, p. 229-233, 1987. 1989.

Scotchmer, Suzanne; Slemrod, Joel. Randomness in tax enforcement. Journal of Public Economics, Amsterdam, v. 38, p. 17-32, 1989.

Siqueira, Marcelo L. Um modelo econômico para análise da evasão fiscal do imposto sobre a renda no Brasil. 2004. 117f. Tese (Doutorado em Teoria Econômica) - Departamento de Economia, PIMES, Universidade Federal de Pernambuco, Recife.

Siqueira, Marcelo L.; Ramos, Francisco S. A economia da sonegação: teorias e evidências empíricas. Revista de Economia Contemporânea, Rio de Janeiro, v. 9, n. 3, p. 555-581, set./dez. 2005.

Slemrod, Joel; Yitzhaki, Shlomo. Tax avoidance, evasion and administration. Working Paper 7473, Boston: National Bureau of Economic Research - NBER, jan. 2000.

Wadhawan, Satish C.; Gray, Clive. Enhancing transparency in tax administration: a survey. African Economic Policy Discussion Paper Number 3, July 1998.

Wasilewski, Luís F. Enfoque tributário da economia informal no Brasil. XIV Concurso de Monografias CIAT/AEAT/IEF, 2001.

Witte, Ann D.; Woodbury, Diane F. The effect of tax laws and tax administration on tax compliance: the case of the U.S. individual income tax. National Tax Journal, Evanston, v. 38, p. 1-13, 1985.

Yitzhaki, Shlomo. A note on income tax evasion: a theoretical analysis. Journal of Public Economics, NorthHolland, v. 3, p. 201-202, 1974. 


\section{APÊNDICE 1 - CONDIÇÕES PARA EXISTÊNCIA DE UM ÓTIMO INTERIOR}

Não se pode assumir, a priori, que $0<\mathbf{X}<\mathbf{R}$, pois, dependendo dos valores dos parâmetros do modelo ( $\mathbf{t}, \mathbf{p}_{1}, \mathbf{p}_{2}, \mathbf{p}_{3}, \alpha, \theta_{1}$ e $\theta_{2}$ ), isto pode ou não ser verdadeiro.

Para se verificar que condições devem ser satisfeitas pelos parâmetros a fim de que se tenha uma solução interior, deve-se avaliar a utilidade esperada em $\mathbf{X}=0$ e $\mathbf{X}=\mathbf{R}$. Como a utilidade marginal esperada é decrescente em $\mathrm{X}$, deve-se ter que:

$$
\begin{aligned}
& \left.\frac{\partial E[U]}{\partial X}\right|_{X=0}>0 \quad \text { e }\left.\quad \frac{\partial E[U]}{\partial X}\right|_{X=R}<0 \\
& p_{1} p_{x} R M g\left(Y_{A}\right) U^{\prime}\left\{\Pi-t R\left[\alpha \theta_{1}+(1-\alpha) \theta_{2}\right]\right\}+ \\
& +p_{1}\left(1-p_{x}\right) R M g\left(Y_{B}\right) U^{\prime}\left\{\Pi-t R\left[\alpha\left(1+\theta_{1}\right)-1\right]\right\}+ \\
& +\left(1-p_{1}\right) p_{2} R M g\left(Y_{C}\right) U^{\prime}\left\{\Pi-t R \theta_{21}\right\}+ \\
& +\left(1-p_{1}\right)\left(1-p_{2}\right) R M g\left(Y_{D}\right) U^{\prime}\{\Pi+t R\}>0 \\
& p_{1} p_{x} R M g\left(Y_{A}\right) U^{\prime}\left\{\Pi+t X\left[\alpha \theta_{1}+(1-\alpha) \theta_{2}\right]\right\}+ \\
& +p_{1}\left(1-p_{x}\right) R M g\left(Y_{B}\right) U^{\prime}\left\{\Pi+t X\left[\alpha\left(1+\theta_{1}\right)-1\right]\right\}+ \\
& +\left(1-p_{1}\right) p_{2} R M g\left(Y_{C}\right) U^{\prime}\left\{\Pi+t X \theta_{21}\right\}+ \\
& +\left(1-p_{1}\right)\left(1-p_{2}\right) R M g\left(Y_{D}\right) U^{\prime}\{\Pi-t X\}<0
\end{aligned}
$$

No modelo de Allingham e Sandmo (1972 - equação 6), para que um contribuinte ache ótimo sonegar é simplesmente necessário que p. $\theta<1$; ou seja, ele irá fazê-lo quando o pagamento esperado da evasão de uma unidade adicional de imposto for menor que a alíquota marginal real.

No presente caso, a relação entre os parâmetros do modelo é um pouco mais complexa, conforme se depreende das expressões A2 e A3, não sendo possível estabelecer uma relação simples entre tais parâmetros para que se tenha um ótimo interior.

Desta forma, será assumido que as relações descritas em A2 e A3 são satisfeitas para os valores reais dos parâmetros encontrados no Brasil, já que não há dúvidas de que $\mathbf{X}<\mathbf{R}$ (existe sonegação do IRPF no Brasil) e não é muito forte assumir que $\mathbf{X}>0$, já que é comum que o contribuinte declare pelo menos uma parte da sua renda tributável.

Para a realização das simulações, o modelo será calibrado de forma a possibilitar somente a ocorrência de ótimos interiores. 


\section{APÊNDICE 2}

X(t) para Diferentes Teta2

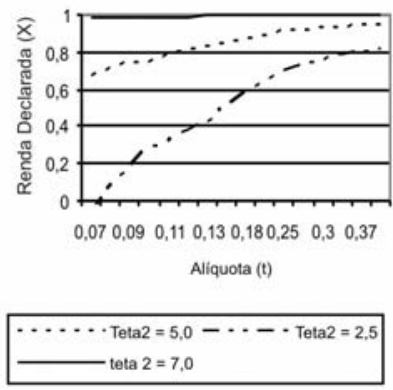

\section{$X(t)$ para Diferentes Teta1}

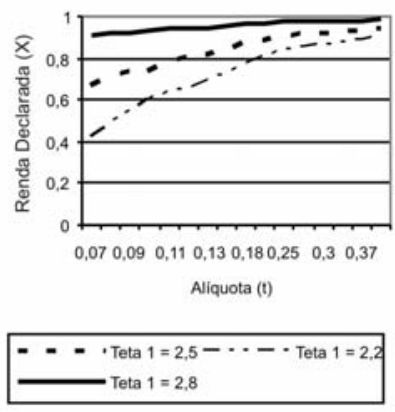

$X(p 1)$ para Diferentes Teta2

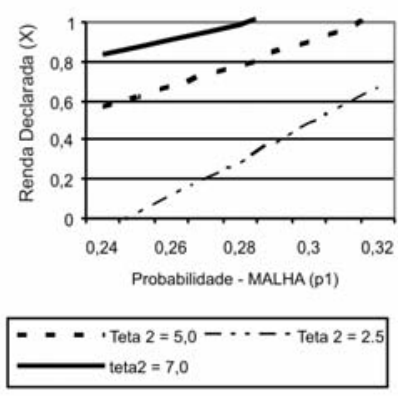

X(p2) para Diferentes p1

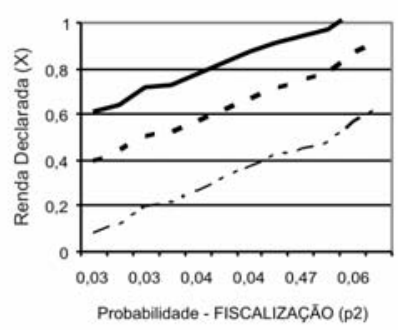

- - - $p 1=27,81 \%-\cdots-\cdot p 1=22,0 \%$ $-p 1=31,0 \%$
$X(t)$ para Diferentes p2

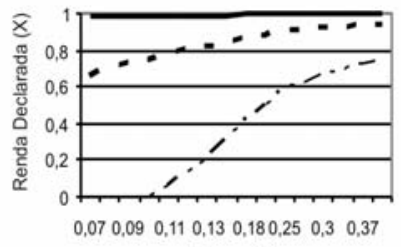

Aliquota (t)

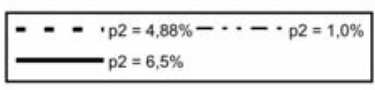

X(p2) para Diferentes Aliquotas
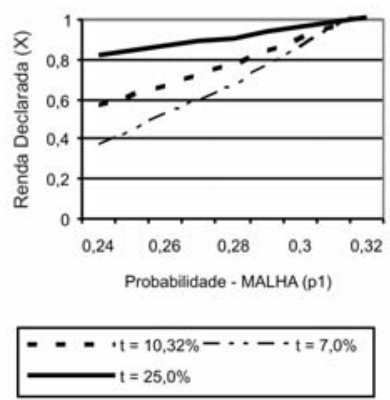

X(p1) para Diferentes Teta1

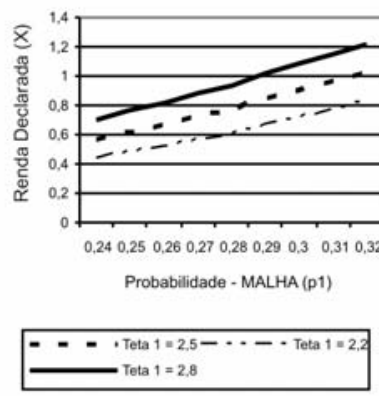

$X(p 2)$ para Diferentes Alfas

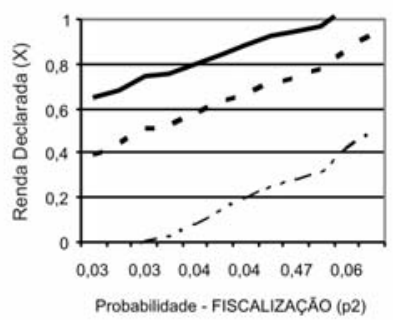

- - Alfa $=70 \%-\cdots-$ Alfa $=50 \%$
$X(t)$ para Diferentes ALFA

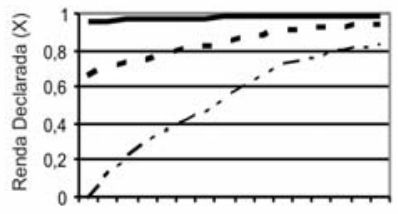

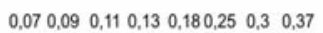
Aliquota ( $t$ )

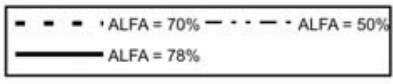

X(p1) para Diferentes p2
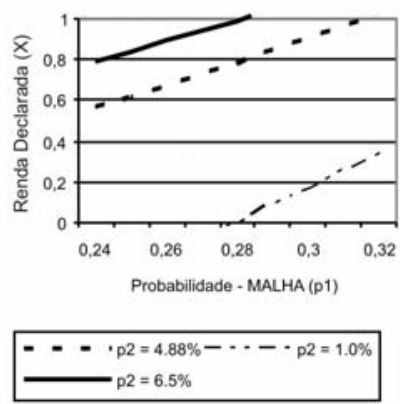

X(p2) para Diferentes Alíquotas

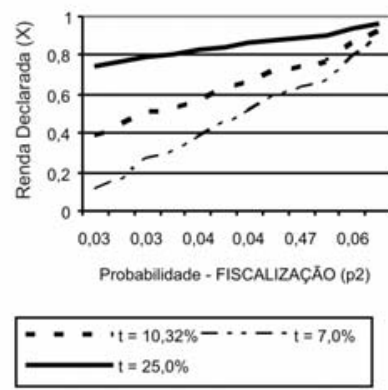

X(p2) para Diferentes Teta1

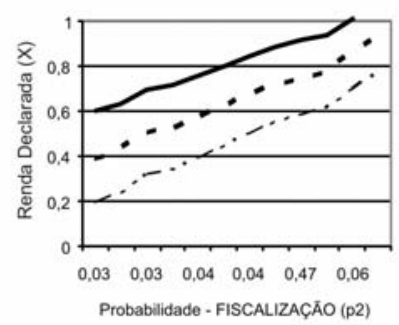

- - - ' Teta $1=2,5-\cdots-\cdot$ Teta $1=2,2$ 


\section{X(Te1) para Diferentes p1}
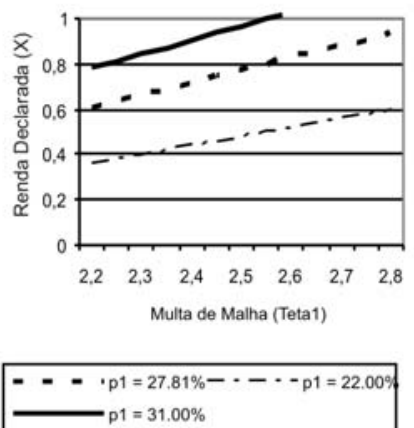

$\mathbf{X}(\mathrm{Te}$ 1) para Diferentes $\mathrm{p} 2$
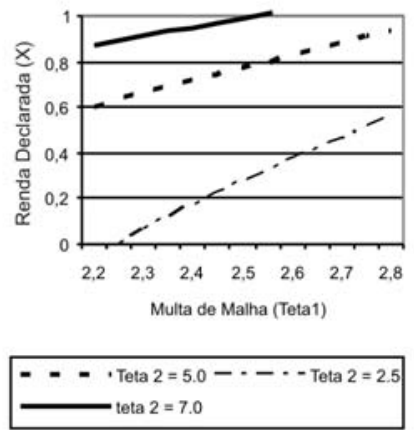

\section{$\mathbf{X}(\mathrm{Te} 2)$ para Diferentes} Alfas

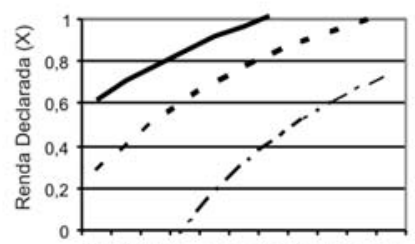

$\begin{array}{lllllllllll}2,5 & 3 & 3,5 & 4 & 4,5 & 5 & 5,5 & 6 & 6,5 & 7 & 7,5\end{array}$ Multa fiscalizaçăo (Teta2)

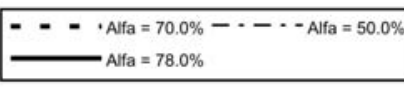

X(Alfa) para Diferentes p2

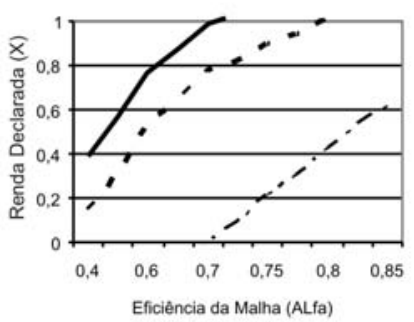

- - - $\cdot p 2=4.88 \%-\cdots-\cdots p 2=1.00 \%$
X(Te1) para Diferentes p2
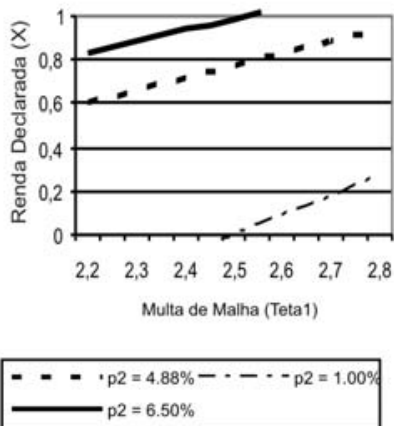

$\mathbf{X}($ Teta2) para Diferentes $\mathbf{p} 1$
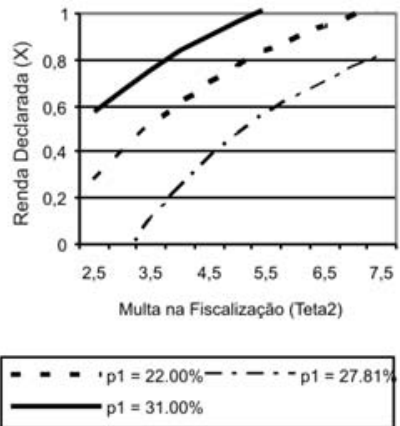

\section{X(Te2) para Diferentes} Aliquotas

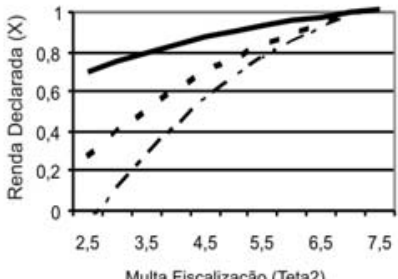

Fiscalizaçâo (Teta2)

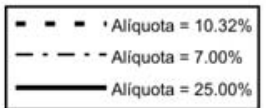

X(Alfa) para Diferentes $t$

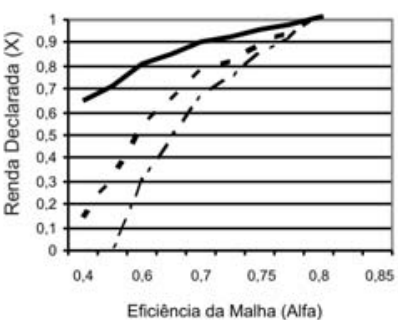

- - - $t=10.32 \%$ - - - $t=7.00 \%$
$\mathrm{X}(\mathrm{Te} 1)$ para Diferentes $\mathrm{p} 2$
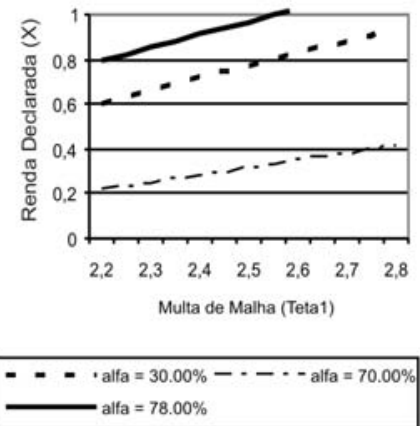

X(Teta2) para Diferentes

p2

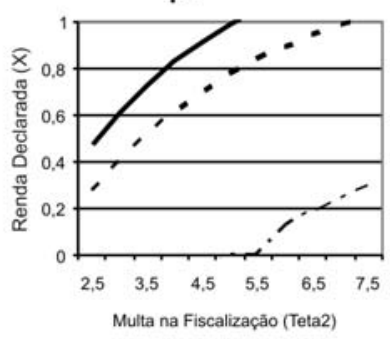

- - - $p 2=4.88 \%-\cdots-\cdots p 2=1.00 \%$ - $22=6.50 \%$

X(Alfa) para Diferentes p1

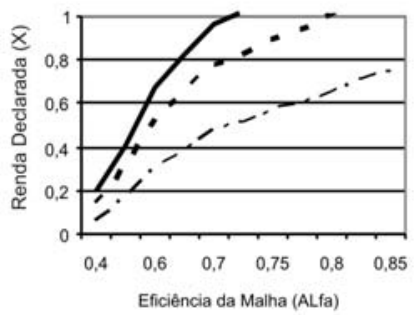

$$
\begin{aligned}
--P p 1=27.81 \%-\cdots-\cdots p 1=22.00 \% \\
\hline p 1=31.00 \%
\end{aligned}
$$

X(Alfa) para Diferentes Teta1

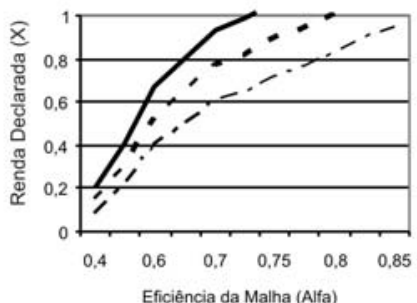

- - - ' Teta1 $=2.5-\cdots-\cdots$ Teta1 $=2.2$ 